\title{
René Millar
}

Instituto de Historia

Pontificia Universidad Católica de Chile

\section{Contrapuntos hagiográficos sobre el Venerable Fr. Pedro de Urraca (Jadraque 1583 - Lima 1657) (*)}

\section{INTRODUCCIÓN}

Pretendemos analizar cuatro hagiografías que en diferentes épocas se escribieron sobre Fr. Pedro de Urraca. Trataremos de determinar los objetivos que perseguían sus autores, las diferencias y semejanzas que presentan las obras, la relación de cada una con el proceso de beatificación y, por último, intentaremos apreciar las orientaciones religiosas que reflejan, distinguiendo los cambios que podrían manifestarse producto de los momentos en que fueron escritas y de los fines perseguidos por los autores.

Las hagiografías son una fuente histórica muy particular, pues si bien se refieren a un personaje real, no pretenden que todos los hechos expuestos sean ciertos desde una perspectiva racional. Y esto porque en la hagiografía lo que importa, como señala Michel de Certeau, es aquello que es ejemplar (1) o edificante, según la expresión de Hippolyte Delehaye (2). Además, tienen un objeto directamente apologético de la figura del protagonista y, de manera indirecta, de la orden o congregación religiosa, sobre todo si aquel llega a ser canonizado, a lo que se supone que también deben contribuir tales escritos (3). No obstante todo lo anterior, las hagiografías constituyen una fuente muy valiosa para incursionar en la mentalidad religiosa y cultural de una época. En ellas encontraremos informa-

(*) Este artículo es producto del proyecto Fondecyt $\mathrm{N}^{\circ} 1060608$.

(**) Agradezco la colaboración prestada por la Señora Magdalena Urrejola Santa María, que fue muy importante en la etapa de recopilación y procesamiento de material. También debo un reconocimiento especial a Fr. José Zaporta, postulador de la causa de Fr. Pedro Urraca.

(1) Michel de Certeau, La escritura de la historia. Universidad Iberoamerica. Departamento de Historia. Ciudad de México. $3^{a}$ ed., 1993, p. 258. Una obra clásica sobre las características del género hagiográfico, en el que se destacan las diferencias con la historia y el papel del pueblo y el hagiógrafo en el proceso creador, es la de Hippolyte Delehaye, Les Légendes hagiographiques. Société des Bollandistes. Bruselas, 1927.

(2) Hippolyte Delehaye, op. cit., p. 64.

(3) Serge Gruzinski - Jean-Michel Sallmann, "Une source d'ethnohistoire: Les vies de <venerables> dans l'Italie méridionale et le Mexique baroques", en Melanges de l'École Française de Rome (MEFRM). Tome 88, 1976-2, p. 791. 
ción sobre valores y creencias imperantes, modelos, sentimientos y aspectos varios de la vida cotidiana (4). En el fondo, la hagiografía no se aleja demasiado de cualquier tipo de texto, ya sea documental o "literario" (género al cual pertenecería aquella), pues, como lo recalca Chartier, ninguno muestra con exactitud la realidad que en principio capta: "La relación del texto con la realidad se construye según modelos discursivos y divisiones intelectuales propias de cada situación de escritura" (5). Considerando los principios y formalidades que enmarcan el género hagiográfico y las motivaciones y conceptos de los autores, la lectura que hagamos de esas obras nos ayudará a ver una "realidad" que no se encuentra habitualmente en otro tipo de documentación.

Las fuentes que utilizaremos son cuatro hagiografías que se escribieron sobre el mercedario Fr. Pedro de Urraca, que murió en Lima, en agosto de 1657, en olor de santidad. La primera la escribió su confesor, Fr. Francisco de Messía, al mes siguiente del fallecimiento, bajo el título de Breve Epítome de la prodigiosa Vida, Muerte y raras maravillas del Penitente y Siervo de Dios, el Ve.Pe.F. Pedro Urraca de la Ss.ma. Trin.d. Hijo del Conv.to de Quito y de esta Prov cia de Lima, del Orn. de N.S. de la Mrd. Redencion de Captivos; permanece inédita hasta ahora. La segunda fue escrita por Fr. Felipe Colombo, cronista oficial de la orden, y la tituló El Job de la Ley de Gracia retratado en la admirable vida del Siervo de Dios Venerable Padre Fray Pedro de Urraca. Fue publicada en Madrid, en 1674 y reeditada en 1790 (6). La tercera, de autor anónimo, se titula Vita del Ven. Servo di Dio Fra Pietro de Urraca. Religioso Professo del Reale e Militare Ordine della Bma. Vergine della Mercede Rendenzione de' Schiavi. No se especifica la fecha en que fue escrita, aunque suponemos que es de comienzos del siglo XIX; también se encuentra inédita. La cuarta, la escribió el mercedario P. Luigi Aquatías, con el título Vida del Ven. Siervo de Dios P. Fr. Pedro Urraca de la SS. Trinidad. Mercedario y se publicó en Roma, en 1976.

Los hagiógrafos conocidos, en consecuencia, son todos mercedarios, planteándose dudas respecto del autor anónimo, pues en el texto no se encuentran referencias que permitan vincularlo a esa religión y, aún más, claramente no lo sería según se desprende del parecer de un miembro de la orden, que también está manuscrito al comienzo de dicha obra. Una copia de esta se encuentra en el archivo de la Curia General de la Orden de Merced en Roma. La versión de la obra de Fr. Francisco Messia que hemos consultado está en la Biblioteca Nacional de Madrid, en la colección de Manuscritos de América.

(4) Antonio García Rubial, "Espejo de virtudes, sabrosa narración, emulación patriótica. La literatura hagiográfica sobre los venerables no canonizados en Nueva España", en La literatura Novohispana. Revisión crítica y propuestas metodológicas. José Pascual Buxó y Amulfo Herrera, editores. Universidad Autónoma de México, Ciudad de México, 1994, p. 90.

(5) Roger Chartier, El mundo como representación. Estudios sobre historia cultural. Gedisa editorial. Barcelona, 2002, p. 40.

(6) Hay una reedición moderna efectuada por Celia Ferrer Tévar, Un alcarreño en América: Fray Pedro de Urraca. Institución Provincial de Cultura "Marqués de Santillana”. Guadalajara, 1988. Contiene el texto completo de la edición de 1764 y además un estudio preliminar sobre Fr. Pedro de Urraca y la obra de Felipe Colombo. 


\section{EL PERSONAJE}

El protagonista nació en 1583 en la villa de Jadraque, que estaba bajo la jurisdicción señorial del Duque del Infantado y espiritual del obispo de Sigüenza, en Castilla. Sus padres, naturales de la villa de Baños de la Rioja, cristianos viejos e hidalgos de solar conocido, disponían de un mediano caudal, como lo evidencia las varias casas, viña y hacienda que poseían. Tuvieron cuatro hijos, siendo Fr. Pedro el menor. Todos manifestaron desde muy jóvenes una intensa inclinación religiosa, en la que la madre, doña Magdalena García, desempeñó un papel muy significativo. Los hagiógrafos destacan el compromiso de mantener la virginidad a toda costa que cada uno contrajo tempranamente, lo que habría puesto en una difícil posición al mayor, que, en virtud de esa condición, fue instado por su padre a casarse (7). Los otros hermanos ingresaron al clero; uno fue cura del pueblo de Angón, en donde siempre permaneció, y el otro, que utilizaba el apellido García, ingresó como religioso a la orden de San Francisco. Este pasó a las Indias con el comisario general Juan Venido, residiendo en la provincia de Quito hasta su muerte. Dicho hermano, de nombre Francisco, fue el responsable de la venida de Pedro a América, pues le pidió a su padre que lo autorizara a acompañarlo en su viaje. Él en una primera reacción negó el permiso, argumentando la juventud de Pedro, pero al poco tiempo cambió de opinión y le facilitó su traslado a Sevilla, a donde llegó cuando su hermano ya se había embarcado. En esa ciudad debió esperar un tiempo hasta que hubiera navío disponible para la travesía.

El joven Pedro tenía en ese entones 15 años y desde su niñez había dado muestras de una profunda religiosidad, que expresaba en una especial devoción a la Virgen y a la Santísima Trinidad, fruto de las enseñanzas de su madre. Desde antes de los ocho años había combinado la asistencia a la escuela con labores de ayuda a sus padres y a los pobres del pueblo. A los 11 años inició sus estudios de gramática y los siguió hasta los 15 , a partir de cuya edad inició su aventura americana. El viaje, según refieren sus hagiógrafos fue muy azaroso y después de muchas peripecias en el que los acontecimientos maravillosos estuvieron constantemente presentes, arribó a Quito, en donde se reunió con su hermano religioso. Este lo inscribió en el colegio de los jesuitas, en el que estuvo dos años prosiguiendo sus estudios. En ese período mantuvo sus prácticas piadosas, que lo llevaban a visitar regularmente los diversos templos de la ciudad, haciendo que su figura llegara a ser conocida por religiosos de diversas órdenes, comenzando por los franciscanos, compañeros de su hermano. Una de las iglesias que más frecuentaba era la de la Merced, por estar consagrada a la Virgen. Allí habría experimentado una visión, que lo impulsó a solicitar su ingreso a dicha orden.

Aceptada su solicitud, tomó el hábito y durante un año estuvo en el Noviciado, tiempo en el que se comportó de manera ejemplar a la hora de observar la obedien-

(7) Obediente a su padre, aceptó hacerlo y de hecho se celebró la ceremonia, pero, tantos habrían sido sus ruegos al Señor y a la Virgen, que ese mismo día, antes de consumar el matrimonio, contrajo una intensa fiebre, de la que falleció pocos días después. Fr. Francisco de Messía, Breve epítome de la prodigiosa Vida.., op. cit., f. 66. También, Fr. Felipe Colombo, El Job de la Ley de Gracia..., op. cit., edición de Celia Ferrer, op. cit., p. 148. 
cia, la humildad, la virtud del silencio, la práctica de la oración y el rigor de las penitencias, a la vez que sufría de manera reiterada los embates del demonio, ante el cual, al decir de los hagiógrafos, nunca habría flaqueado, gracias a la ayuda de la Virgen, su protectora. Pasado el año, el 2 de febrero de 1605, con el nombre de Fr. Pedro de la Santísima Trinidad hizo la profesión, con lo que se obligaba a observar los cuatro votos solemnes: obediencia, pobreza, castidad y, en el caso de su orden, la redención de cautivos. En el convento realizará las humildes labores de portero y sacristán, amén de limosnero, en el ejercicio de cuya labor debió efectuar un viaje muy agitado por los pueblos de la comarca. Al ordenarse de epístola, el visitador circunstancial del convento de Quito dispuso su traslado a Lima, a la Recoleta de Belén, recién fundada por la orden para acoger a los religiosos que buscaban una observancia más rígida de la regla.

En el viaje a Lima, además de los sucesos maravillosos que le ocurrieron, tuvo un significativo encuentro, cerca de Trujillo, con el marqués de Montesclaro, que venía a hacerse cargo del gobierno del virreinato. Fue el propio virrey, al saber su presencia en las cercanías, quien lo mandó buscar, posiblemente a instancias de una camarera que lo acompañaba, quien en España había conocido a los padres de Fr. Pedro. En la comitiva también iba, como capitán de la guardia del marqués, don Francisco Messia, padre del futuro hagiógrafo del Siervo de Dios, que le habría dicho que, en esas regiones, ya era opinión común su santidad y virtudes. El virrey y su mujer le pedieron insistentemente al religioso que los acompañara en su viaje a Lima, pero este prefirió seguir el camino solo. Con todo, ese encuentro marcó el inicio de una singular relación con la corte virreinal, que el religioso mantuvo en el tiempo con diversos virreyes y que incluso, durante el posterior paréntesis peninsular, lo llevó a vincularse con importantes miembros de la corte madrileña.

Una vez en el convento de recoletos mercedarios de Belén, se destacó por la obediencia a los prelados y el rigor de sus penitencias, que se manifestó entre otras prácticas en el uso de un cilicio de cadenas de hierro que, en forma de jubón, le ceñía desde la cintura hasta los hombros. A pesar de sus reticencias, por sentirse indigno, se ordenó de evangelio y de sacerdote en obediencia a lo mandado por los superiores. Cantó misa el día de la Asunción del Señor por instrucción expresa del virrey marqués de Montesclaro, quien asistió expresamente y fue su padrino. Para recuperarse de una grave enfermedad que lo aquejó, sus prelados lo enviaron al convento de Trujillo. La estadía se prolongó un tiempo debido a la rebeldía de los achaques, que lo obligó a una larga convalecencia que alternó entre la doctrina de Paisán y Trujillo. Repuesto en parte, logró autorización para salir a recolectar limosna para el convento y para la redención de cautivos, en cuyo viaje experimentó algunos sucesos extraordinarios, que tampoco faltaron durante su estadía en aquella ciudad. Uno de estos correspondió al insólito encuentro con el nuevo virrey Príncipe de Esquilache, que veía a asumir el gobierno y que acababa de desembarcar en Paita (8). A instancia del virrey, Fr. Pedro se integró a su comitiva

(8) Según los hagiógrafos, Fr. Pedro pidió autorización para ir a Paita, porque sabía que el nuevo virrey, que estaba por llegar, quería verlo. Por su parte, una vez que desembarcó Esquilache habría preguntado por Fr. Pedro sin saber si estaba en Lima o Trujillo. Lo cierto, es que Fr. Pedro lo habría estado esperando en su mula, en el lugar del desembarco. 
en el viaje hacia Lima. Una vez allí, acudía con regularidad a palacio a dirigir espiritualmente a damas de la corte y a la princesa, de quien fue su confesor y a quien dedicó uno de los libros de espiritualidad que escribió (9), el que también utilizó en su labor sacerdotal en algunos conventos de monjas, en donde tuvo muchas hijas de confesión. El virrey Esquilache, al cumplir su período, en 1621, pidió a los prelados que le diesen licencia a Fr. Pedro para que acompañara a su familia a España, lo que efectivamente aconteció.

Instalado en el convento de la orden en Madrid, desarrolló una intensa labor en el confesionario y como guía espiritual de numerosos devotos. Durante su residencia madrileña coincidió con algunos insignes maestros de espíritu de la Orden, entre los que se destacaba quien fue su mentor y amigo Fr. Juan Falconi. También, en ese tiempo fue muy significativa su relación con la corte, reflejada en el acceso frecuente al palacio real, en donde confesaba a las damas camareras de la reina y de manera especial a la propia soberana Isabel de Borbón, que le tenía en mucha estima. No obstante, en la corte se sentía incómodo y más todavía por no poder hacer realidad su aspiración de ir a Berbería a redimir cautivos, a causa de los obstáculos que le pusieron las camareras de la reina. En 1726 consiguió autorización para regresar a Perú, gracias a que su solicitud coincidió con la decisión del Capítulo General de la orden de realizar una reforma en dicha provincia, para lo cual designó un vicario general y a Fr. Pedro, como hijo de ella, para que lo auxiliara (10). El viaje de regreso también estuvo marcado, según indican sus biógrafos, por hechos prodigiosos. En Lima tuvo una gran acogida de los fieles, que llenaban el templo para verle. En esta etapa vivió en el convento principal de la orden y a instancia suya lo acomodaron en una de las celdillas que usaban los hermanos legos y en la que no tuvo más que un camastro y una mesilla con unas imágenes de papel y un Cristo de plomo. Realizó una activa labor apostólica, a pesar de las enfermedades que poco a poco lo fueron incapacitando físicamente y que en parte fueron consecuencia de las rigurosas penitencias a las que se sometía.

Durante este período se manifestaron con intensidad sus dones sobrenaturales, especialmente los de profecía y sanación. A ellos se agregó la visión de cosas extraordinarias, como fue la de unas cruces, que lo estimularon a promover la devoción a la Santísima Cruz, donando una reliquia al convento de las monjas de Santa Catalina y pequeñas cruces de madera a hijos de confesión y fieles que le pedían, por sus supuestas virtudes curativas. La etapa final de su vida la pasó en la enfermería y su incapacidad física, por artritis, gota y otros males, llegó a tal extremo que le impedía incluso comer por sí mismo, aunque, llevado en andas al altar, era capaz de decir misa. Predijo su muerte y se preparó para recibirla, permaneciendo 28 días sin comer, recibiendo solo la eucaristía y algo de agua. Finalmente falleció el 7 de agosto de 1657 rodeado de los miembros de la comunidad y en medio de la congoja de sus numerosos devotos. Sus exequias generaron una grandiosa manifestación de fervor, asistiendo a ella no solo las máximas autoridades civiles y religiosas, sino

(9) Fr. Pedro de Urraca, Breve compendio de modos suaves y fuertes para andar al alma amorosamente importunando a Dios (Lima, 1616). Reedición comentada. Roma, s/f.

(10) Fr. Felipe Colombo, op. cit., p. 197. 
también cientos de fieles que se disputaban por hacerse con alguna reliquia del Siervo de Dios, al que aclamaban como santo. Diversos hechos maravillosos relacionados con curaciones milagrosas y visiones extraordinarias se produjeron al momento de su entierro y en los días inmediatamente siguientes.

\section{LOS AUTORES}

El criollo Fr. Francisco Messía Ramón, nacido en Loja en el obispado de Quito, en 1626, fue el primer hagiógrafo de Urraca. Era hijo de Francisco Messía de Sandoval, natural de Écija, caballero de la orden de Calatrava y ex capitán de la guardia personal del virrey marqués de Montesclaro, y de doña Magdalena García Ramón, natural de Cuenca, en la Audiencia de Quito, encomendera en Huarochirí (11). Fr. Francisco, que tenía un hermano homónimo (12), era religioso de la orden de la Merced, donde desempeñó los cargos de maestro, comendador del convento grande de Lima y provincial en dos oportunidades. También fue calificador del Santo Oficio y por lo mismo era considerado como teólogo. Gracias a su condición de confesor de Urraca dispuso de abundante información para elaborar la hagiografía, que la concluyó el 20 de septiembre de 1657, al mes siguiente de la muerte del Siervo de Dios. La escribió a requerimiento de los superiores, pero es evidente que tenía un interés particular en hacerlo dada su admiración por el personaje y el interés que puso en la gestación y desarrollo de su causa de beatificación. Era frecuente en la época que muchas hagiografías fueran escritas por personas que tenían un vínculo especial con el biografiado; por lo general, lo hacía alguien que lo había conocido personalmente, compañero de religión, director espiritual o confesor (13). ¿La pertenencia a la elite social y la condición de criollo del autor habrán influido en el texto que escribió? En diversos estudios historiográficos se ha sostenido que las "Vidas" escritas por naturales de América tendieron a reflejar la identidad criolla (14). ¿Estará presente ese fenómeno en la obra de Messía? Por otra parte, el autor ¿para qué publico escribía? ¿Lo hacía para la elite o pensando en el conjunto de la sociedad, incluso para los que no sabían leer? Más adelante trataremos de dar respuesta a esas interrogantes. Las fuentes que utiliza son declaraciones orales de personas que lo conocieron y testimonios escritos de otros que se los hicieron llegar al enterarse que recopilaba material para escribir su "Vida"; pero lo

(11) Rafael Sánchez-Concha Barrios, “Ascendencia del virtuoso limeño Alonso Messía Bedoya, de la Compañía de Jesús (1655-1732)”. Hidalguía. Revista de genealogía, nobleza y armas. $\mathrm{N}^{\circ} 321$, pp. 243-270. Revista académica de historia y genealogía del Instituto Salazar y Castro, Madrid, España. Marzo-abril del 2007.

(12) Fue capitán, encomendero, corregidor, alcalde Lima en 1670 y finalmente familiar del Santo Oficio en 1674. Ver Rafael Sánchez-Concha, op. cit.

(13) Ronald J. Morgan, Spanish American Saints and the Rhetoric of Identity 1600-1810. The University of Arizona Press. Tucson, 2002, p. 23. Desde el siglo XIV se habían multiplicado las vidas de santos escritas por testigos cercanos al sujeto, como el confesor o el capellán, y en el siglo XVII fueron muy frecuentes y varias alcanzaron mucho renombre. Ver René Aigrain, L'hagiographie. Ses sources - Ses méthodes. Son histoire. Reimpresión. Société des Bollandistes. Bruxelles, 2000, p. 314 y 351-353.

(14) Ibid. 
más importante fue el conocimiento personal del biografiado, que enriqueció a través del tiempo con preguntas que le hacía acerca de su vida (15).

El segundo hagiógrafo fue el mercedario Fr. Felipe Colombo, nacido en Guadalajara, Castilla, en 1623. Hijo del alcaide de la cárcel de la ciudad y de Ana del Yerro. Ingresó muy joven en religión, lo que puede significar que era hijo segundón o que la situación económica familiar era estrecha. En la orden hizo una destacada carrera hasta alcanzar los cargos de Maestro General y Definidor General. Murió en 1684, pero diez años antes era el Cronista General de la Orden y en tal condición escribió la obra sobre Urraca, que fue una más entre las numerosas que elaboró sobre la Orden misma, sobre algunos destacados miembros de ella, amén de otras de teología e incluso sermones y censuras. Especial mención merece su Historia General del Real i Militar Orden de Nuestra Señora de la Merced Redención de Cautivos, de la que alcanzó a terminar solo el primer tomo, que quedó inédito. También escribió las biografías de San Pedro Pascual (1673), de San Pedro Nolasco (1674), de San Ramón Nonato (1676) y de Fr. Gonzalo Díaz de Amarante (1676) (16). La obra sobre Urraca se publicó en Madrid en 1674, aunque él hubiera querido que fuera su primer libro, dada su relación de paisanaje con el biografiado. Se atrasó su publicación porque el texto se alargó y además tuvo problemas de financiamiento. La escribió, 17 años después de la muerte del Siervo de Dios, a instancias de los superiores, que se la encargaron una vez que Fr. José Sanchis, quien había asumido inicialmente la tarea, no pudo continuarla por sus responsabilidades como obispo de Segorbe y Maestro General de la Orden (17). Este religioso le aportó documentación valiosa que había logrado recopilar y al parecer también algunas páginas que había alcanzado a redactar. Sin embargo, será la obra de Messía la fuente principal de su trabajo; a eso agregó documentación que recogió en el archivo de la orden en Madrid y algunos papeles que le habrían hecho llegar desde Lima.

Del tercer autor es muy poco lo que podemos decir. Como ya lo adelantamos, desconocemos su nombre e incluso también la fecha en que escribió el manuscrito de 289 páginas, aunque consideramos que puede ser de comienzos del siglo XIX. Esto porque cita, en varias partes del texto, declaraciones de testigos del proceso de beatificación a partir de la Positio Super Virtutibus presentada ante la Sagrada Congregación de los Ritos y publicada en Roma en 1807 (18). Todo parece indicar que no es mercedario, pues un miembro de la Orden, que escribió un comentario de tres páginas y que anteceden al manuscrito, lo expresa de manera indirecta al decir que el autor desconoce la manera como es el trato que se dan los miembros al interior de la misma. Dado que el texto está en italiano, puede que el autor sea de esa nacionali-

(15) Francisco Messía, op. cit, f. 179.

(16) Celia Ferrer Tévar, op. cit., p. 53 y ss.

(17) Fr. Felipe Colombo, El Job de la Ley de Gracia... op. cit., advertencia al lector. El padre José Sanchis había nacido, al parecer, en Valencia, en 1622 y falleció en 1694, siendo arzobispo de Tarragona. Ingresó a la Orden en 1636 y profesó en 1638. Fue elegido provincial en el capítulo de 1659 y consagrado obispo en 1672. Ver El Puig de Santa María. Hoja parroquial. Real Monasterio de Santa María de El Puig (Valencia). Año II, 3 de marzo, 1963, No 40.

(18) En la Peculiares Dilucidationes ex Officio Concinnatae, Roma, 1973, p. 19, el relator general de la causa estima que la obra es posterior a la segunda mitad del siglo XVIII porque en la página 137 se refiere al ya beatificado Simón de Rojas, que lo había sido en 1766. 
dad, ya que no existe referencia a una versión en castellano y posterior traducción. El comentarista mercedario es muy crítico de la obra, fundamentalmente porque el autor confundió el segundo nombre del biografiado: De la Santísima Trinidad, con la orden religiosa del mismo nombre. Esa equivocación, que afloraría en varias partes, y otra confusión referente a la orden a la que pertenecía un beato, pueden hacer pensar que el autor no era eclesiástico. Pero por otra parte, el texto deja en evidencia que el autor tenía un buen conocimiento de las escrituras y de los padres de la Iglesia, a los que cita con frecuencia, por lo que no podría descartarse aquella condición. Dice haber utilizado como fuente dos manuscritos, el del padre Sanchis y el del padre Messía, omitiendo cualquier referencia a Colombo, lo cual no deja de ser extraño; en todo caso, refiere algunos hechos de la vida de Urraca que no están en Messía y sí en Colombo (19). Como hemos indicado, también extrae información de los testimonios de los testigos de la causa de beatificación.

El cuarto y último autor que consideramos es el mercedario Luigi Aquatías, natural de Guayaquil y nacido en 1897 en el seno de una familia acomodada, de origen francés por parte de padre, quien era un rico hacendado. Después de haber estudiado algunos años en el colegio mercedario de Guayaquil, ingresó al noviciado de la orden en Quito, en 1911. Hizo la profesión solemne en 1917, ordenándose de sacerdote en 1923. Desempeñó diversos cargos en la provincia, desde maestro de novicios hasta provincial. Al haber sido nombrado Asistente General de la Orden viaja en 1938 a Roma, permaneciendo en ella hasta su muerte en 1985. Solo en dos oportunidades volvió a América, en viajes breves, a cumplir labores de Visitador General de las provincias de Ecuador y Chile. En Roma, en la Curia General de la Orden, ocupó en diversas ocasiones el cargo de Consejero General, pero sin duda el que más significación tuvo para él y al que más tiempo dedicó fue el de Postulador General, que lo ejerció entre 1946 y 1984. En esa condición presentó y activó las causas de beatificación de varios candidatos de la Orden, o vinculados a la misma, ante las congregaciones de los Ritos y de las Causas de los Santos. Entre ellas le correspondió reiniciar la causa de Fr. Pedro de Urraca, en relación con la cual reeditó, con comentarios personales, una obra de espiritualidad del candidato y también elaboró la biografía que debía adjuntarse al proceso en cumplimiento de lo establecido por la Congregación de la Causas de los Santos y que se publicó en Roma en 1976 (20). Las fuentes que utilizó el padre Aquatias fueron el Summarium del proceso que se encuentra en la Positio Super Virtutibus y las obras de Messía y Colombo (21).

\section{ESTRUCTURAS, FORMALIDADES Y OBJETIVOS}

Las tres primeras obras tienen en lo fundamental una estructura bastante similar. La mayor diferencia entre ellas está en la parte preliminar, que es extremadamente

(19) Al respecto una digresión a propósito del nombre de Pascual con el cual lo bautizaron y que menciona Colombo, op. cit, p. 184.

(20) Fr. Enrique Angulo Vela, "P. Luis Aquatías Gallegos". Boletín de la Orden de la Merced. Enerodiciembre 1985, pp. 164-166.

(21) Luigi Aquatías, op. cit., p. 13. 
extensa en la obra de Messía y bastante más reducida en Colombo y todavía más en el autor anónimo. En ninguno de estos prolegómenos falta la protesta de los autores en que dicen someterse en todo a lo dispuesto por su Santidad el Papa Urbano VIII en los decretos (1625-1634-1642) referentes a la publicación de libros que refirieran hechos de personas con fama de santidad o milagros y revelaciones sin que hubiese existido un reconocimiento oficial de la calidad de hombre santo por parte de la Sede Apostólica. Los hagiógrafos señalaban que el uso de ese tipo de términos en sus obras tendría un significado solo natural sin que implicara asumir o dar por válidas situaciones sobrenaturales, las que como señalaba Messía solo comprometían al autor y no a la Iglesia. Esta declaración la efectuaban para cumplir con la legislación que así lo exigía y en la práctica se transformó en un mero formulismo de los autores para permitir que sus obras lograran circular y no se las prohibiera por hacer santo a quien no lo era; pero en el fondo estaban convencidos de que los hechos referidos implicaban a un sujeto que gozaba de dones sobrenaturales, independiente de que la calidad de santo no le hubiese sido aún reconocida por la Santa Sede.

Messía dedica la obra al Rey Felipe IV, a quien se la envía nada más acabarla (22), posiblemente como una manera de ganarse su adhesión para la causa de beatificación de Urraca. Colombo, por su parte, hace lo propio con Pedro de Portocarrero, Conde de Medellín, y que en ese entonces era Presidente del Consejo de Indias, con el pretexto de haber nacido Urraca en las tierras de los señores de la casa de Mendoza, antepasados del conde; también lo justifica en razón de la conveniencia que tiene que el Presidente de dicha institución conozca el aporte de la orden de la Merced en general y de uno de sus miembros en particular al proceso de incorporación de los territorios del Nuevo Mundo a la Monarquía y a la Iglesia. Pareciera que con esta acción, el autor buscaba congraciarse con el poder, ganar influencia, ya sea para obtener apoyos financieros que requería para sus publicaciones, o con el objeto de disponer de padrinos en su carrera al interior de la orden y también fortalecer los vínculos de esta con la autoridad.

En la parte preliminar de estas dos obras también se incluyen, como era habitual en aquellas de tipo religioso, las licencias eclesiásticas de publicación. En el caso de Messía la otorgan el provincial de la Orden Pedro de los Ríos y el Arzobispo de Lima Pedro de Villagómez, previa censura y aprobación de dos informantes. Para la obra de Colombo la licencia la conceden Fr. Ramón de Morales, a nombre del provincial de Castilla, y Francisco Corteza, a nombre del ordinario de Toledo. Pero lo más interesante de estos prolegómenos se encuentra en la obra de Messía. En ella figura un número muy significativo de pareceres, censuras y aprobaciones dadas a la obra, a solicitud del autor, por diversas personalidades eclesiásticas e incluso laicas. El autor buscó que hubiese representantes de las más importantes órdenes religiosas, del cabildo catedralicio, de la Universidad, de los colegios mayores y de la Real Audiencia. La importancia de este apartado, en el contexto general de la obra es tan relevante que de un total de 269 folios que la componen, nada menos que 60 corresponden a las opiniones de los diversos consultores aprobando y

(22) Fr. Francisco Messía, op. cit., f. 199. Es posible que ejemplar de esta hagiografía que se encuentra en la Biblioteca Nacional de Madrid corresponda al que se le hizo llegar al Monarca. 
recomendando su publicación. ¿Cuál fue la razón para que Messía procediese de esa forma? Nos parece que este tenía dudas de que se concretara la publicación de su obra. No podemos olvidar que era calificador del Santo Oficio y que esta institución también había publicado los decretos referentes a libros sobre "Vidas" de santos y en ellos se le entregaban facultades para la revisión de ese tipo de escritos (23). La orientación que le había dado a la biografía de Urraca aparecía en contradicción con lo establecido en dichos decretos y con las políticas referentes a las hagiografías que se imponían en la Europa católica de la época (24). Para tratar de asegurarse la publicación intenta cumplir con todas las formalidades exigidas por la legislación; por eso incluye al final de su obra una segunda protestación explicando el alcance y sentido con que había usado los términos en cuestión, pues así estaba establecido en el decreto de Urbano VIII de 1642 (25). Por lo mismo, no se conformó con las autorizaciones normales, sino que a ellas sumó las opiniones de reconocidos doctores y autoridades para que avalaran su obra. Esta situación no se produjo con el libro de Colombo porque las contradicciones con las normas, como veremos más adelante, estaban atenuadas; además tenía el respaldo de las máximas autoridades de la orden, gozaba de la cercanía con las altas esferas del poder y el mismo al parecer tenía bastante influencia (26). En último término la publicación de una hagiografía, no solo dependía de la autorización dada por el Ordinario del lugar, sino que ese informe favorable debía enviarse a la Santa Sede, que era la quedaba la autorización definitiva (27).

También las obras de Messía y Colombo presentan entre ellas algunas diferencias en la parte final, en la manera como las concluyen. Así, mientras el primero incorporaba copia de testimonios de diversas personalidades exaltando la calidad de hombre virtuoso de Urraca, con lo que reafirmaba lo señalado por los informantes de la parte preliminar y evidenciaba una vez más la necesidad que tenía de adjuntar pruebas de autoridad que validaran la imagen que daba del sujeto; el segundo hacía una descripción, con referencias históricas, del convento de Lima y de sus miembros más destacados, en un afán por engrandecer a la religión que hizo posible que germinara ese fruto tan valioso que fue Pedro de Urraca. Este mismo autor cierra su obra incluyendo una nómina de personas de prestigio que exaltaban las virtudes de Fr. Pedro que la obtuvo de la parte preliminar de la obra de Messía.

Como ya indicamos, el resto de la estructura de las tres primeras obras es muy similar. Responden en ese aspecto a un modelo, que se viene reiterando desde la Baja Edad Media y que sigue a su vez el esquema desarrollado por los autores de biografías de la antigüedad grecorromana, especialmente Suetonio con sus Vidas de

(23) Mágnum Bullarium, SS. Pontoficum Urbani VIII \& Inocentii X. Constituciones Complectens. Lugduni, 1692, p. 83.

(24) Jean-Michel Sallmann, Naples et ses saints à l'âge baroque (1540-1750). Presses Universitaires de France. Paris, 1994, p. 57. Éric Suire, La saintité française de la Réforme catholique (XVIeXVIII siècles). Presses Universitaires de Bordeaux. Pessac, 2001, p. 26 y 36-37. Ronald J. Morgan, op. cit., p. 30.

(25) Francesco Leone, La prova documentale degli scritti nei processi di beatificazione e canonizzazione (Studio storico-canonico). Istituto di Scienze Religiose "F. de Santa". Roma, 1989, p. 34.

(26) Celia Ferrer Tévar, op. cit., p. 55

(27) Francesco Leone, op. cit., p. 29. 
los doce césares (28). La fórmula consiste en dividir la obra estructuralmente, más allá de los capítulos o libros, en dos partes muy definidas: una que sigue un desarrollo cronológico y la otra, que es temática. En el caso de las hagiografías, en esta segunda se trata del ejercicio de las virtudes y de los dones sobrenaturales del sujeto; específicamente en las obras que analizamos, los autores se refieren a los ejercicios ascéticos que practicaba Urraca, a las formas de oración que seguía, a las visiones, profecías y dones taumatúrgicos que tenía. La primera parte, a su vez, se puede dividir en varias etapas: se inicia con el nacimiento, niñez y juventud; sigue con la vida como religioso, con sus diversos estados y labor apostólica y espiritual; y culmina con la enfermedad, muerte y hechos extraordinarios asociados a ella, junto con la fama póstuma de santidad de que gozó. El libro del padre Aquatías, en cambio, tiene una estructura un poco diferente pues sigue hasta el final el orden cronológico, culminando por tanto con la muerte y funerales del personaje, aunque en algunas partes incorpora capítulos temáticos en los que explica la práctica de sus virtudes. Como ya veremos, ese no es el único aspecto en el que esta obra, por responder a las políticas oficiales sobre la santidad, propias del siglo XX, se aleja de las hagiografías anteriores.

En cuanto a los objetivos que persiguen los autores con sus respectivas obras resultan coincidentes en lo fundamental. Así, todos pretenden contribuir a la santificación oficial del Siervo de Dios, aunque lo hacen en función de la época y circunstancias en que las elaboran. Messía, que escribió su obra pocos días después de la muerte del personaje, la concluye, como hemos indicado, con una segunda protestación, todavía más específica que la del comienzo. En ella, resguardándose de los decretos del Papa Urbano VIII entre otras cosas dice: "no pretendo por estas mis narraciones, introducir o aumentar algún culto o veneración al dicho o fama y opinión de santidad, ni añadir alguna cosa a su propia estimación, ni hacer escalón para su futura beatificación o canonización en algún tiempo o comprobación de milagro" (29). Pero ¿esto que afirma era realmente así? Todo parece indicar que el autor buscaba, con esas palabras, evitar que se impidiera la publicación de su obra, más que reflejar el fondo de su propósito. Si lo que señala fuera su parecer íntimo ¿qué sentido tendría entonces el libro? Messía se manejó con bastante habilidad, pensó bien el punto. En ninguna parte hace declaración de objetivos, no dice nada que lo pueda comprometer, a lo más dice que lo escribió "por precepto de la obediencia", es decir por mandato del superior (30). Y que él espera que la Santa Sede, "cuando convenga, ilustrada del Espíritu Santo" declare la santidad de Urraca y valide lo que refiere en el libro en cuanto a sus portentos, que, como su padre espiritual, los supo de su propia boca (31). En este último planteamiento y en otro en que también hace referencia a su futura canonización, para cuyas celebraciones espera que Lima lo declare como su patrono (32), se refleja el objetivo que siempre persiguió al escribir la obra: la oficialización de su santidad. Está ya señalado, él lo

(28) Ronald J. Morgan, op. cit., p. 25.

(29) Fr. Francisco Messía, Breve epítome de la prodigiosa Vida..., op. cit., f. 269v.

(30) Ibid., f. 13.

(31) Ibid., f. 258.

(32) Ibid., f. 257v. 
dice de manera oblicua, pero no así varios de los informantes del libro y de quienes le hicieron llegar papeles con sus opiniones, que por cierto van incluidas en la obra. Unos aluden a su pronta canonización, otros dicen remitir su testimonio para aportar antecedentes para la pronta apertura del proceso informativo (33). Es más o menos claro que Messía, con su obra, que tuvo amplia circulación, tanto en Lima como en Quito (34), buscaba generar un ambiente favorable a la apertura de informaciones con miras a su beatificación, a pesar de no reconocerlo expresamente en el texto.

La publicación del libro de Colombo coincide con el término del proceso ordinario, por lo que la obra está escrita en función del próximo proceso apostólico. De hecho, el que este libro se publicara y no así el de Messía es un indicador de que la orden, en la medida que era un encargo oficial, tenía dudas sobre la influencia del Epítome en la causa y por ello avaló el de Colombo, que matizaba algunos de los sucesos extraordinarios contenidos en aquel y se adelantaba a justificar ciertos comportamientos del biografiado que podrían ser criticables. Dicho autor dice estar "esperando el tiempo en que, con la declaración de la Iglesia Apostólica Romana, por medio de su Santísima Cabeza, puedan publicarse, decirse y creerse sus virtudes, sus maravillas, sus milagros y prodigios, sin el contrapeso de la falibilidad humana" (35). Esa obra se reeditó en 1790, coincidiendo con una reactivación del proceso apostólico que había estado paralizado por 76 años. El autor anónimo, por su parte, escribe con posterioridad a la Positio de 1807 y posiblemente cerca de las Congregaciones preparatorias de 1816 y 1821, con el objeto de influir en ellas enfatizando el ejercicio de las virtudes y los dones recibidos por el candidato. Por último, el libro de Aquatías fue escrito a instancias de la Sagrada Congregación de los Santos; su autor, en esa época, era el postulador de la causa, el cual pretendía que el nuevo proceso culminara positivamente (36).

Por cierto que los autores perseguían otros objetivos con sus obras. El renombre personal fue uno de ellos y si bien no lo expresan de manera evidente, puede inferirse de algunos párrafos y del contexto de la obras. Colombo, en la dedicatoria y en la presentación al lector hace gala del trabajo que ha desarrollado como cronista; al respecto, refiere los esfuerzos que ha gastado en escribir sobre la conquista y evangelización del Nuevo Mundo y, "llevado de mi genio", en recopilar información para contar la historia de la orden, uno de cuyos tomos ya terminó. Y agrega que con el tiempo irá sacando algunos libros para parecerme en algo "al escritor que dijo Cristo, Mateos 23" (37). Messía, a su vez, destaca su papel como confesor y confidente del Siervo de Dios (38), al punto de tener presencia en el texto, pues relata muchos hechos como actor secundario o testigo de vista, lo que termina por realzar su figura (39), pero siempre dejando claro quién es el verdadero protagonista. Es

(33) Ibid., fs, 39v.251.

(34) Ibid., f. 261. También, Fr. Felipe Colombo, op. cit., p. 262.

(35) Fr. Felipe Colombo, op. cit., p. 279.

(36) Fr. Luigi Aquatías, op. cit., dedicatoria, p. 5.

(37) Fr. Felipe Colombo, op. cit., p. 142.

(38) Dice Messía que lo que escribió lo supo de su propia boca, pues el Siervo de Dios se había fiado de él como su padre espiritual, op. cit., f. 258

(39) Por ejemplo, dice en f.271v: "Arriba dejo referido el suceso que me sucedió con el P. Fr. Pedro acerca del Testamento espiritual". 
evidente que el autor adquiere una gran notoriedad, asociada a la fama del santo, y él no la elude sino que la destaca al hacer mención a la labor que desempeñó como intermediario con los seguidores de Fr. Pedro y en la recopilación de material con vistas a la apertura de informaciones para su futura causa de beatificación y, sobre todo, al narrar hechos que lo tuvieron como protagonista. Al respecto debe señalarse que un capítulo completo, el 30, lo plantea en esos términos. Lo titula: "De algunos casos particulares que a mí me sucedieron con el P. Fr. Pedro"; y en un párrafo del mismo, expresa: "No es posible reducir a número los casos que me sucedieron con personas afligidas que venían a consultar al P. Fr. Pedro en negocios graves, echándome por tercero para que le pidiese los encomendase a Dios" (40). Incluso Messía llega al extremo de incluir un documento suyo titulado "Testamento espiritual", con la excusa de que el Siervo de Dios le había hecho un comentario sobre él (41). En suma, nuestro autor adquiere una fama, ya sea porque la buscó conscientemente o como consecuencia indirecta del relato que hace en cuanto confesor del sujeto.

Asociado con esto nos encontramos con otro fenómeno, el del rol que juega el autor-confesor al escribir la hagiografía de su hijo espiritual. Messía se sentía cumpliendo un misión, no solo respecto de sus prelados sino también de la Divinidad, que lo había "puesto en ocasión de comunicar, confesar y asistir tantos años a un hombre tan prodigioso...Quiere su Da. Md. Dolerse de mí para que mi vida y todas mis acciones la emplee en su santo servicio" (42). El comenzó a preparar la obra, y posiblemente a escribirla, antes de la muerte de Urraca, pues señala que le preguntaba cosas de su vida "para ir apuntando los sucesos de ella" (43). El escrito en su conjunto tiende a mostrar la imagen de un sujeto excepcional tanto por la práctica de algunas virtudes como por los dones de que gozó por merced Divina. En la actitud, objetivos y comportamientos de Messía, se aprecia una diferencia significativa con el papel desempeñado por los confesores en cuanto autores de "Vidas" de religiosas. En este tipo de casos, el confesor-autor se transforma lisa y llanamente en protagonista, pues la "santidad" de la monja, es decir la riqueza de su vida religiosa solo se explicaría en función de la intervención del director espiritual, que marca la pautas de comportamiento y orienta el texto en relación con ellas, todo en el contexto de una política de control de la religiosidad femenina (44).

Los autores también procuran prestigiar a la orden religiosa, que acogió e hizo posible que allí se desarrollara una vida tan excepcional. En ese aspecto, Messía no es muy explícito, pero en el texto queda clara la estrecha relación entre la Orden, con su particular vínculo con la Virgen, y la santidad de Urraca. El autor enfatiza que el ingreso en esa religión obedeció a una señal de la madre de Dios; destaca la gran acogida que tuvo de la comunidad y del prelado cuando ingresó al noviciado; constantemente está repitiendo que su vida la arregló siguiendo el modelo de San Pedro

(40) Fr. Francisco Messía, op. cit., p. 178v.

(41) Ibid., fs. 218-228.

(42) Ibid., f. 184.

(43) Ibid., f. 179.

(44) Darcy Donahue, "Writing Lives: Nuns and confessors as auto/biographes in Early Modern Spain”, en Journal of Hispanic Philology. N ${ }^{\circ} 13,1989$, p. 232-233. Otro análisis interesante de la relación entre hagiógrafo-confesor y religiosa en Asunción Lavrin, "La religiosa real y la inventada: diálogo entre dos modelos discursivos", en Historia y Grafía, Universidad Iberoamericana, $N^{\circ} 14$, México, 2000. 
Nolasco, de quien fue muy devoto (45); hace presente que nunca tuvo dificultad alguna con sus superiores, maestros y compañeros; en el fondo, muestra cómo la orden le proporcionó los medios y le facilitó el ejercicio de sus virtudes, sin poner el menor obstáculo, pues lo valoró siempre como un ser que gozaba del favor de Dios. Bastante más directo a la hora de expresar este objetivo resulta Fr. Felipe Colombo, quien titula uno de los capítulos iniciales de la siguiente manera: "Del viaje que hizo a las Indias y su prodigiosa vocación a la Orden de la Virgen de la Merced". También destaca la acogida que tuvo en el convento de Quito y en los demás en que permaneció y la identificación con la vida de San Pedro Nolasco. A todo ello agrega las referencias continuas a miembros destacados de la orden y en muchos casos se detiene en describir con cierto detalle la labor que habían realizado. Incluso más, culmina la obra con tres capítulos dedicados a reseñar la crónica del convento de Lima, "donde vivió y murió el Venerable Padre". En ella menciona a numerosos religiosos que se destacaron por haber servido al Monarca, por su capacidad intelectual o por su vida espiritual, como Fr. Gonzalo Díaz de Amaranto y el propio Fr. Francisco Messía.

Al igual que el común de las hagiografías, estas, además de lo señalado con anterioridad, estaban pensadas en función de los lectores. Messía quería que su obra se publicara y por lo tanto esperaba que llegara a un público más amplio que el constituido solo por clérigos, como hasta mediados del siglo XVII había sido la tendencia predominante en Francia (46). Aunque dicho autor no lo manifiesta directamente en el texto, sí lo señalan algunos de los informantes, quienes propugnaban su pronta publicación porque estaban ciertos de que iba a servir de estímulo a la perfección espiritual de los fieles (47), sobre todo, porque, como lo indica el cura de la catedral de Lima, tendría más eficacia por corresponder a alguien que trataron y conocieron más de cerca (48). Por otra parte, la obra estaba destinada a que circulara entre quienes conocieron a Urraca para que se comprometieran en su proceso de beatificación. Este fenómeno quedó en evidencia en las declaraciones de varios testigos de la causa que reconocieron haber leído la obra de Messía (49). A su vez, en la aprobación de la obra de Colombo se señalaba que su publicación ayudaría a "encaminar las almas por la senda estrecha de la virtud". Y por último el Padre Aquatías aspiraba a que su obra también sirviera de modelo a los fieles en general y a los aspirantes de la Orden en particular. En las dos primeras hagiografías no se habla abiertamente de que sirviera de modelo, pues había conciencia de que no era una vida que se pudiera imitar en su conjunto, pues era "rara, prodigiosa" y llena de portentos y "maravillas singulares" (50). Algunos de los comentaristas son bastante

(45) Fr. Francisco Messía, op. cit., f. 85.

(46) Éric Suire, op. cit., p. 46.

(47) Fr. Francisco Messía, op. cit., fs. 19 y 32

(48) Ibid., f.61.Informe del Dr. Lucas de Palomares.

(49) Los testigos P. Martín Rodríguez, Pascual Alonso Hernández, P. Juan Bara y Don Juan Nicolás Roldán dicen haber leído la obra de Messía sin que se lo preguntaran. Summarium Super Dubio, en Positio Super Virtutibus, Roma 1959, pp. 9, 28, 79 y 361.

(50) Ibid., f. 24. Censura de Fr. Cipriano Medina, de la orden de Predicadores. Por su parte el visitador del arzobispado de los Reyes Francisco Gamarra espera que quien la lea alabe a Dios en sus maravillas y "el devoto halle materia dulce a su recreo, el distraído reforma a la corrección de sus costumbres... y unos y otros hallen en tal estampa el ejemplar mejor que imitar, las huellas más puras a seguir en la carrera de esta vida para parar felizmente en la otra", op. cit., f. 40. 
cautos al respecto. Uno señala que la lectura permitiría que Urraca se transformara en maestro de los más versados y aprovechados en teología mística y de guía de aquellos penitentes que luchaban para no caer en el Infierno; amén de que sería bueno que la gozaran los fieles en general para que se conocieran los frutos del cristianismo en estas tierras (51). Otro estimaba que la obra ayudaría a la "edificación de los fieles y mayor honra de Dios" (52). Sin embargo, eso no ocurre con la última hagiografía, pues la imagen que en ella se presenta del biografiado sí era factible de que pudiese ser un ejemplo.

\section{CONTENIDOS}

\section{A) Lo maravilloso y sobrenatural en Messía}

\section{- $\quad$ Elegido por Dios}

Las cuatro obras tienen sus peculiaridades en materia de contenidos o del tratamiento de los temas. Al leer a Messía lo primero que salta a la vista es el papel que en su obra tiene lo sobrenatural. Toda ella está henchida de acontecimientos maravillosos, confirmando la validez de su título que nos anuncia "la prodigiosa vida, muerte y raras maravillas del penitente y Siervo de Dios...". En todo caso, los títulos de las hagiografías por lo general incluían alguna expresión relacionada con algo fuera de lo común. Así la clásica de Hansen sobre Santa Rosa se titula "Vida admirable..."; la de Fr. Bernardo Medina sobre Martín de Porres, "Vida prodigiosa..." y la de José Buendía sobre el jesuita Francisco Castillo, se denomina "Vida admirable y prodigiosas virtudes..." (53). Lo anterior reflejaría cuán frecuente era que en las hagiografías estuviera muy presente el tema de lo sobrenatural, que se confundía con lo maravilloso, según destaca Hippolyte Delehaye, y para quien el fenómeno estaría asociado al sentir popular, que tendría debilidad por esas expresiones y que el hagiógrafo no hacía más que recoger (54). Pero en el caso de Urraca, el texto muestra que toda su vida, desde su nacimiento hasta su muerte, está marcada por lo extraordinario, lo maravilloso, por lo que se escapa a lo común, dejando en un plano muy secundario al factor natural. En la presentación que Messía hace de esos fenómenos debemos distinguir entre los acontecimientos que son producto de los dones sobrenaturales o de la intervención de seres sobrenaturales y los que son resultado de la propia acción excepcional del personaje.

(51) Ibid., f. 28. Informe de Fr. Diego de Trejo.

(52) Ibid., f. 42v. Informe de Fr. Nicolás de Ulloa.

(53) Leonardo Hansen, Vida admirable de Santa Rosa de Lima. Patrona del Nuevo Mundo (Roma, 1664). Vitoria, 1929. Fr. Bernardo Medina, Vida prodigiosa del Venerable Siervo de Dios Fray Martín de Porras, de la Tercera Orden de N. Glorioso P. Santo Domingo. (Lima, 1663). Editorial Jus, México, 1964. José de Buendía, Vida admirable y prodigiosas virtudes del venerable y Apostólico Padre Francisco del Castillo, de la Compañía de Jesús, natural de Lima, Ciudad de los Reyes en la Provincia del Perú. Madrid, 1693.

(54) Hippolyte Delehaye, op. cit., p. 47. Teófanes Egido sostiene que lo maravilloso era inherente a las hagiografías del Barroco; específicamente dice que en ellas constituían uno "de los reinos de la fantasía", ver "Hagiografía y estereotipos de santidad contrarreformista (La manipulación de San Juan de la Cruz)”, en Cuadernos de Historia Moderna, № 25, monográfico, 2000, p. 70. 
Al igual que en la generalidad de las hagiografías, Messía presenta al sujeto como elegido por Dios para su glorificación. Toda la vida de Urraca está en función de ese papel glorificador. Eso fluye de la labor que realiza, de su comportamiento y de las maravillas que hace por merced divina. De la lectura de la obra queda la sensación de que el camino que seguiría su vida lo tenía más o menos marcado desde su nacimiento, pues todas las virtudes estaban en él desde su niñez y juventud. Se daría en Urraca una especie de predestinación a la santidad, fenómeno por lo demás que está también muy presente en las hagiografías de santos europeos de la Época Moderna (55). La libertad del sujeto se difumina en un suceder de acontecimientos en los que la intervención del Ángel de la Guarda, de los santos de su devoción, de la Virgen y de Dios le van marcando el camino y lo ayudan a superar las dificultades y a hacerlo siempre vencedor ante las tentaciones y peligros diversos (56).

La elección divina se reflejaría en el hecho de haber nacido en una familia noble, de cristianos viejos y de una acendrada religiosidad, en donde la madre tenía marcada en su piel nada menos que la rueda de navajas de Santa Catalina de Alejandría (57) y gozaba del don de la sanación. Los hermanos del Siervo de Dios dieron muestras permanentes de vida cristiana y ejercieron las virtudes de manera excepcional, especialmente la de la castidad. Un tío por parte de madre, cura de Jadraque, fue famoso por el ejercicio de la caridad y a su muerte, que la anunció, se vieron luces en el cielo (58). El relato de la niñez y juventud de Urraca nos muestra un sujeto que por haber nacido en ese hogar tuvo una educación que lo marcará por el resto de su vida. $\mathrm{Su}$ madre será quien lo guíe por la senda de la fe, iniciando su formación a edad muy temprana. Le inculcó el temor a Dios y de manera especial el amor a la Virgen. Antes de los seis años aprendió la doctrina cristiana y realizaba ejercicios ascéticos, tales como la abstinencia (59). También desde esa época quedó en evidencia que gozaba de la protección de la madre de Dios. Ella oyó sus ruegos expresados ante una imagen que la representaba, y lo salvó de una peste que asolaba a España (60). A partir de ahí se iniciará una relación con la Virgen, con la que mantendrá frecuentes diálogos, en los que recibirá orientaciones de vida; pero también, en determinados momentos, ante solicitudes expresas, obtendrá auxilio físico. A los nueve años le acontece otro hecho que también tendrá proyecciones para el resto de sus días. Estando con unos amigos encaramado en una alta encina, se quebró la rama que lo sostenía y cayó al vacío. En el trayecto de la caída se encomendó a la Santísima Trinidad y tuvo la visión de tres

(55) Jean-Michel Sallmann, op. cit., p. 238. Teófanes Egido destaca este aspecto en relación con las hagiografías sobre San Juan de la Cruz, op. cit, p. 78.

(56) Sobre el fenómeno de la predestinación en la santidad, ver Eric Suire, op. cit., pp. 79-80.

(57) Esta santa del siglo IV fue martirizada con una rueda de cuchillas para tratar de obligarla a desistir de su fe.

(58) Francisco Messía, op. cit., cap. 1.

(59) El autor, al destacar el papel de la familia en la formación religiosa de los niños-santos, coincide con lo que al respecto expresa la generalidad de las "Vidas" escritas sobre la santidad en la España Moderna, ver Isabelle Poutrin, "Souvenirs d'enfance l'apprentissage de la saintete dans l'Espagne Moderne”, en Melanges de la Casa de Velásquez, t. XXIII, 1987, p. 333 y ss.

(60) La intervención de la divinidad o la Virgen para salvar la vida del niño santo afectado por una grave enfermedad es una escena frecuente en las hagiografías sobre santos napolitanos de la Época Moderna. Ver Sallmann, op. cit., p. 238. 
luces, como estrellas, formando un triángulo, que desaparecieron cuando llegó a tierra, sin un rasguño. A partir de ese momento se hizo devotísimo de la Santísima Trinidad, al punto que al profesar lo adoptará como nombre de religión.

\section{- $\quad$ Las tentaciones}

Cuando llegó la etapa en que el joven debía comenzar a tomar decisiones personales aparecerá otro elemento que tendrá gran protagonismo en el resto del relato. Urraca, con 15 años, se mostró dispuesto a ir a las Indias para reunirse con su hermano religioso, que había venido enviado por su orden. En el viaje fue salvado de morir ahogado en dos oportunidades por intervención directa de la Virgen, a raíz de lo cual hizo ante ella voto de ser religioso (61). Poco tiempo después, mientras cruzaba el istmo de Panamá, ensimismado diciéndole requiebros a la Virgen, sufrirá un ataque del demonio, que, bajo la figura de un negro que echaba fuego por los ojos (62), lo desbarrancó de la senda y lo hizo caer a las correntosas aguas de un río, desde donde lo rescató su Ángel de la Guarda. A partir de ahí, el demonio nunca más lo dejará tranquilo, pasando a ser actor muy importante del relato. Se lo representará de diversas maneras, ya sea como una bestia horrible, caballo furioso, serpiente o gigante (63). Y aparecerá sobre todo en los momentos en que Urraca debía tomar decisiones importantes sobre su vida, como cuando ingresó al noviciado en Quito, o cuando le correspondía hacer votos de la profesión o en el trayecto de sus distintos viajes en busca de limosnas para los cautivos y el convento. En el fondo, el papel del demonio era tratar de torcer o hacer fracasar el proyecto que Dios y la Virgen tenían diseñado para Urraca. Las tentaciones serán uno de los recursos preferidos, las que estimularán la envidia, la lujuria y la soberbia. También a veces el diablo tratará de quitarle la vida y con frecuencia lo someterá a castigos brutales, para que pierda la paciencia y capitule. El autor describe con detalles las golpizas que el demonio le dio en diversas oportunidades en su celda, al ruido de las cuales sus compañeros entraban a ver qué pasaba y se encontraban al religioso en el suelo, semiconsciente y adolorido. En otras oportunidades lo atacaba en el claustro del convento o en alguno de los patios, incluso en el coro de la Iglesia, en las noches que iba a tomar disciplinas o a orar (64). Pero Urraca, con el apoyo constante de la Virgen, vencerá al demonio una y otra vez, a tal punto, que este vio que había algunos ámbitos en donde nada podía hacer, por lo que desistió de insistir en ellos, como aconteció con las tentaciones deshonestas que después de un tiempo que las tuvo en el noviciado nunca más las sufrió (65). En ese campo fue donde "más experimentó los favores que le hacía la Reina de los Ángeles" (66).

(61) Ibid., f. 70v.

(62) El demonio, desde la Baja Edad Media, fue frecuentemente representado como un negro de rasgos atemorizantes, de hecho ese color fue característico de él ( J. Delumeau, op. cit., p. 376) y se le asociaba a impureza, en contraposición a lo blanco y puro. De un hombre pecador se decía con frecuencia que tenía el alma negra.

(63) Uno de sus hermanos fue tentado por el demonio en forma de una joven mujer deshonesta, pero él no experimentó ese tipo de tentación. Messía, op. cit., f. 66v.

(64) Ibid., cap. 21

(65) Ibid., f. $165 \mathrm{v}$.

(66) Ibid., f. 77 
Las tentaciones que experimenta Urraca se inscriben en la tradición hagiográfica heredada de la Baja Edad Media. El sujeto, en su calidad de servidor de Dios, necesariamente debía luchar para hacer prevalecer el bien sobre el mal, tanto en la sociedad como en su propio ser. De acuerdo con las Sagradas Escrituras, los mejores en la observancia de los mandamientos y el cumplimiento del mensaje de Jesús serían los que más sufrirían los embates del demonio (67). Las virtudes y las gracias o dones sobrenaturales constituían las armas de que disponían para ganar el combate al pecado y al demonio que lo promovía (68). Las hagiografías desempeñaron un papel muy importante en la difusión de la figura del demonio y la labor que desempeñaba en relación con los hombres, al tratar de que cayeran en el pecado (69). El modelo que seguirán los hagiógrafos modernos, incluido Messía, será la Vida de San Antonio Abad, escrita por San Atanasio, vulgarizada por la Leyenda áurea de la Vorágine (70) y que nuestro autor y Urraca conocerán en la versión del Flos sanctorum del padre Ribadeneira; obra que tenían, leían y comentaban (71). Este autor describe con detalle las tentaciones de San Antonio, sus controversias dialécticas con el demonio y las golpizas que le daba junto con sus ministros (72). El paso de las tentaciones a los golpes fue muy frecuente en las vidas de los santos y serían la reacción de impotencia del demonio ante la imposibilidad de hacer caer al Siervo de Dios, es decir de corromperlo (73). Por lo mismo, lo que el hagiógrafo refiere de Urraca no resultaba extraño a la mentalidad de la época; los fieles estaban muy al tanto de las vidas de los santos por la lectura de los Flos Sanctorum o colecciones de biografías y por la iconografía en que se representaba a santos sufriendo las tentaciones del demonio. Sin ir más lejos, Fr. Bernardo de Medina, el hagiógrafo del venerable peruano Martín de Porres, relata sus confrontaciones con el demonio, quien habría usado con él los mismos procedimientos que en su tiempo empleó con San Antonio y Santa Catalina de Siena (74). Y en un cuadro del convento de Santo Domingo de Lima está representado Martín de Porres, resistiendo la tentación del demonio. Rosa de Santa María también experimentó los acosos del demonio, con el que tuvo diversos lances, al igual que los experimentados por la santa de Siena, como lo refiere el hagiógrafo de la santa limeña (75). Al

(67) Apocalipsis 12 .

(68) Éric Suire, La saintité française de la Réforme catholique (XVIe-XVIIIe siècles). Presses Universitaires de Bordeaux. Pessac, 2001, p. 220.

(69) Ibid., p. 222.

(70) Jean Delumeau. El miedo en Occidente (siglos XIV-XVIII). Una ciudad sitiada. Taurus. Madrid, 2002 , p. 366.

(71) Fr. Francisco Messía, op. cit., f. 180. Ambos eran asiduos lectores de vidas de santos. Messía dice que él leía siempre la correspondiente a cada día.

(72) Pedro de Ribadeneira, Flos sanctorum de la vida de los santos. (Hay una edición de Madrid de 1604). Barcelona, 1790, t. I, pp. 178-187.

(73) Éric Suire, op. cit., p. 231.

(74) Fr. Bernardo Medina. Vida Prodigiosa del Venerable Siervo de Dios Fray Martín de Porras, de la Tercera Orden de N. Glorioso P. Santo Domingo. (Lima, 1663). Editorial Jus, México, 1964, p. 116. El acoso a que fue sometida Catalina de Siena por el demonio nos muestra que en su arremetida contra los santos no había distinción de género. Eric Suire, op. cit., p. 230. También, Fernando Cervantes, El diablo en el Nuevo Mundo. El impacto del diabolismo a través de la colonización Hispanoamericana. Herder, Barcelona, 1996, p. 162.

(75) Fr.Leonardo Hansen, Vida admirable de Sta. Rosa de Lima. Patrona del Nuevo Mundo (Roma, 1664), Vitoria, 1949, cap. XVII. También existen cuadros de Santa Rosa resistiendo al demonio, ver Fernando Cervantes, op. cit., p. 172. 
decir de Éric Suire, las tentaciones constituían un elemento necesario en la vida de los santos por ser signos de una virtud sólida (76); incluso, mientras más vehemente era el acoso del demonio más prestigio tenía quien lo sufría, considerándose una instancia útil en la camino de la salvación (77).

El texto de Messía, en lo referente al demonio, también pudo estar influido por el libro de Job, que el hagiógrafo lo tenía muy presente, pues, al referirse a la virtud de la paciencia de Urraca, lo califica como un nuevo Job (78). En consecuencia, la imagen del demonio tentando al Siervo de Dios en torno a las cosas que más valoraba, como era su compromiso con la Orden, responde a la forma como se le presenta en el libro sagrado. El diablo lo tienta en la medida que Dios se lo permite y como Urraca finalmente lo vence, termina incrementando su riqueza, es decir, gana en virtud y en valoración ante la divinidad. Messía escribe lo siguiente después narrar una violenta golpiza que el Siervo de Dios recibió del demonio: "Se fue a la capilla y en ella estuvo dando gracias a Nro. Señor por el favor que le había hecho de dar licencia al demonio para que lo maltratase" (79). Pero el éxito de Urraca fue posible no solo por sus virtudes y gracias de que gozaba y que lo impulsaban a practicar la oración y la mortificación, sino porque con frecuencia tuvo el auxilio de su Ángel de la Guarda. De acuerdo al pensamiento teológico, los demonios estaban permanentemente asediando a los hombres, por lo que estos necesitaban tener siempre un ángel a su lado que los protegiera, aunque ello no garantizaba que no cayeran en el pecado, porque por afecto al mismo podían desoír las inspiraciones de sus custodios; en casos extraordinarios, por gracia especial de Dios podían hacerse visibles a los hombres o intervenir haciendo milagros (80). Esto era lo que ocurría con Urraca, cuyo Ángel de la Guarda cumplía instrucciones de Dios. Pero todavía de mayor significación era el auxilio permanente que nuestro personaje recibía de la Virgen, en una acción de reciprocidad ante la intensa devoción que siempre le manifestó. Mantenía constantes diálogos con ella, ya sea en su celda o en el templo y con frecuencia tales expresiones, que eran una forma de oración, culminaban en éxtasis. El destacado papel que la Virgen desempeña en los enfrentamientos de Urraca con el maligno también está en consonancia con la misión que el Apocalipsis de San Juan le asigna a Ella en la lucha que el demonio tiene contra quienes observan los mandamientos de Dios y guardan el mensaje de Jesucristo (81).

\section{- $\quad$ Las virtudes o gracias santificantes}

En el relato de Messía se produce una situación interesante en cuanto a la manera como presenta la práctica de las virtudes y el alcance de los dones gratuitos de que gozó el Siervo de Dios. Si nos remitimos a las virtudes, les da un tratamiento desigual. Destaca mucho algunas y a otras ni siquiera se refiere de manera directa;

(76) Éric Suire, op. cit., p. 222.

(77) Fernando Cervantes, op. cit., p. 171.

(78) Fr. Francisco Messía, op. cit., f. 172.

(79) Fr. Francisco Messía, op. cit., f. 85v.

(80) Santo Tomás de Aquino. Suma Teológica. Primera parte, q. 113, art. 1.

(81) Apocalipsis 12. 
deben inferirse del comportamiento general del sujeto. Hace mención de cada uno de los cuatro votos a los que se comprometió como religioso mercedario. Pero en el que más se detiene es en el de pobreza, aunque por otra parte no es mucho lo que refiere al respecto. Dice que no disponía más que de dos hábitos y los muebles de su celda eran solo un camastro y una mesilla, donde tenía una imagen de Cristo en plomo y dos dibujos en papel, uno de la Santísima Trinidad y otro de la Virgen. Agrega que aunque no salía a la calle a pedir, recibía muchas limosnas; sin embargo, jamás habría tocado un ducado con sus manos y esos dineros siempre habrían sido destinados a la redención de cautivos, al sustento de la Orden, al auxilio de mujeres pobres, a sacar de su situación a mujeres mal avenidas, a la fundación de capellanías, al financiamiento de retablos del templo y a otras obras necesarias para el convento. En cuanto a la obediencia, la resume en la siguiente frase: "jamás se le conoció voluntad propia" (82); le dedica de manera específica un poco más de una página, pero en diversas partes del texto hace más de alguna referencia. De la castidad dice todavía menos y lo fundamenta en que nunca había tenido en su vida pensamiento voluntario contra la virginidad y más todavía después de la derrota que le infringió al demonio cuando estaba en el noviciado, a raíz de la cual no lo volvió a tentar con ese tipo de pensamientos. No deja ser especial lo que expone Messía en ese ámbito, pues las pasiones de la carne eran uno de los grandes enemigos de la santidad de la Europa Moderna (83). Del cuarto voto, específico de la Orden de la Merced, la redención de cautivos, hace presente que siempre estuvo en su pensamiento y trató de ir a tierras de infieles a redimir cristianos, pero por diversas circunstancias no lo pudo realizar, aunque fue muy diligente en la obtención de limosnas para ese fin.

Las gracias santificantes, asimismo, tienen un trato diferenciado. Solo se refiere a algunas en apartados específicos y sobre la mayoría trata en diversos momentos y capítulos. Las que más resalta, explicando que las ejercitó en grado heroico, son la humildad, la caridad, la paciencia y la templanza. Urraca, al decir de Messía, siempre se habría considerado indigno de ser religioso, de ser sacerdote y de desempeñar cualquier oficio que no fuesen los más humildes del convento, como sacristán y portero. La virtud de la caridad la centra en la oración, a la que Urraca dedicaba muchas horas del día y de la noche, y a través de la cual manifestaría todo su amor a Dios y al prójimo; rezaba de manera especial por los pecadores y por los enfermos. Y consideraba que la oración era "la puerta principal por donde se entraba a buscar la gracia” y que a través de ella era posible alcanzar los auxilios divinos (84).

El autor señala que desde muy niño practicó la abstinencia, estimulado por su madre. En el ayuno fue muy riguroso, sobre todo para la cuaresma y semana santa, y era frecuente que en el convento pasara tres o cuatro días sin alimentarse. Nunca rehusó una invitación a comer en casa de algunos hijos espirituales, pero siempre refregaba sus dedos, los labios y los platos con acíbar o con polvos que dejaban amarga la comida. Antes de morir, estuvo 28 días en ayunas y solo se alimentó

(82) Fr. Francisco Messía, op. cit., f. 162.

(83) Éric Suire, op. cit., pp. 225-228

(84) Fr. Francisco Messía, op. cit., f. 167v. 
con la comunión y escasos sorbos de agua, lo que el hagiógrafo atribuye a una decisión voluntaria y no como resultado de sus enfermedades. El ayuno, en consecuencia, fue uno de los aspectos importantes en la vida ascética de Urraca, al igual que en la de otros servidores de Dios del Nuevo y del Viejo Mundo, lo que mostraría que no es fácil distinguir entre las prácticas femeninas y masculinas al respecto, a diferencia de lo planteado por Rudolph Bell, quien enfatiza la rigurosidad con que lo practicaban las mujeres virtuosas italianas, al punto de verlo como una peculiaridad de su tipo de santidad (85). Aunque por otra parte, podría percibirse una diferencia en ese punto entre las "Vidas" de hombres y mujeres si lo vemos a partir de lo sostenido por Carolina Walker Bynum para la Europa medieval, en cuanto a que el tema del comer o no comer constituía el aspecto central de las hagiografías de ellas (86). Es claro que la cuestión del ayuno, siendo importante para Urraca, no forma parte de aquellos temas a los que la obra de Messía da mayor significación.

Uno de los aspectos de la vida de Urraca que más destaca el hagiógrafo fue el de las mortificaciones. Desde que entró en religión se sometió a rigurosísimas penitencias, dándose continuas y violentas disciplinas, cuyos golpes retumbaban en el coro del templo. Ya estando en el noviciado usó de cilicios, primero uno áspero de cerdas regalado por su hermano, el que, una vez en Lima, remplazó por otro metálico, con cadenas, que mandó hacer a un herrero. Este le quedó tan ajustado "como si fuera de sogas", que con el tiempo (lo llevó durante 30 años) se le fue introduciendo entre las carnes y le provocó profundas heridas (87). ¿Qué lo llevaba a mortificarse de ese modo? Messía refiere que lo hacía por amor al prójimo (88) y a Dios, pues se consideraba un gran pecador que solo por la misericordia divina no lo mataban a palos. Además, Urraca era un ferviente devoto de la Pasión de Cristo. Frente a su imagen de plomo hacía sus meditaciones, que giraban en torno al sacrificio en la cruz. Las mortificaciones serían, desde su perspectiva, una pálida imitación de los sufrimientos de Cristo, para así poder valorar más la obra que había hecho por la salvación de los hombres (89). De esa manera, el comportamiento de Urraca responde a la valoración que desde fines de la Edad Media, tenía la figura de Cristo en la espiritualidad de sectores cada vez

(85) Rudolph M. Bell, Holy anorexia. The University Chicago Press. USA, 1985. Con todo, este autor señala que a partir del siglo XVII ese fenómeno habría disminuido drásticamente, op. cit., p. 151.

(86) Carolina Walker Bynum, Holy Feast and Holy Fast. The religious significance of food to medieval women. University of California Press, USA, 1987, pp. 94-95. Otro tipo de diferencias estaría en el carácter más discreto de las prácticas masculinas respecto a las realizadas por las mujeres. Éric Suire, op. cit., p 101. Jean-Michel Sallmann, op. cit., p. 271.

(87) Para una fiesta del Corpus, el superior le dijo que contribuyese a cargar el anda de una imagen muy pesada, lo cual hizo soportando todo el peso sobre uno de los hombros en el que le cruzaban las cadenas de su cilicio. Experimentó dolores terribles que estuvieron a punto de hacerlo perder el conocimiento durante la procesión; se sobrepuso, pero Messía dice que "desde entonces le dio el mal de la perlesía (parálisis), que le duró hasta que murió", op. cit., f. 110. Como dice Sallmann, los venerables hacían prueba de una imaginación sin límites cuando se trataba de inventar instrumentos destinados a la automortifiación, op. cit., p. 270.

(88) Messía dice que se azotaba por los pecadores, op . cit., f. 96.

(89) Fr. Francisco Messía, op. cit., f. 169v. 
más amplios de la Iglesia, sobre todo española (90). Con todo, en relación con el mismo tema, la función de las mortificaciones que nos muestra esta hagiografía se aleja de los patrones habituales de la época. Se recurría a ella para controlar las pasiones, sobre todo las de la carne (91). Pues bien, dado que Urraca no se vio afectado por ese tipo de arrebatos, el libro omite esa relación. Por otra parte, es evidente que Urraca habría tenido un cierto desprecio por su cuerpo, que se reflejaría no solo en las mortificaciones a que lo sometía, sino también en el exagerado pudor que exteriorizaba. Mostrarse desnudo era una de las mayores pruebas a que lo podían someter. El biógrafo destacó con mucho énfasis la preocupación que siempre tuvo Urraca por no mostrar nada de su piel y evitar el desvestirse incluso para dormir (92). Refiere el gran dolor que sentía cuando, muy enfermo, necesitaba de la ayuda de terceros para satisfacer sus necesidades (93). Es posible que esta imagen que proyecta Messía y la propia actitud del sujeto, respondan a una mentalidad que también estaba presente en los "santos" franceses de la Época Moderna, en virtud de la cual el menosprecio al cuerpo estaba asociado a la contradicción entre las aspiraciones a la vida eterna y lo perecedero de aquel y del mundo visible (94).

Pero sin duda, la virtud que ejercitó de manera más heroica fue la paciencia. Numerosas páginas están destinadas a mostrar con mucho detalle las enfermedades y padecimientos que fue experimentando a lo largo de su vida. Muchos, como hemos visto, producto de su afán de autoflagelación, pero otros enviados por Dios, según decía, aunque más de alguno podía ser consecuencia indirecta de las mortificaciones. Lo cierto, es que la lista de males que le afectaron es amplia y varios de ellos se fueron superponiendo hasta hacer de él una persona completamente inválida, incapaz de valerse por sí mismo. Messía dice que sufrió de perlesía, es decir, una forma de parálisis, con temblor de los miembros del cuerpo; también tuvo gota, que le afectó los pies, tobillos, rodillas, hombros, codos, muñecas y dedos de las manos, los que terminaron completamente torcidos; y además habría padecido lepra, que le generó unas costras como "escamas de pescado grande", bajo las cuales se criaron colonias de piojos (95); a todo ello se le sumaron tres profundas llagas que le llegaban hasta los huesos y que se le produjeron en ambas caderas y otra a la altura de los riñones. Cuando ya no podía moverse y deseaba comunicarse con sus hijas de confesión y sus devotos lo trasladaban en una mula, en la que se mantenía montado mientras estaba en el lugar; tiempo después cuando su enfermedad empeoró lo llevaban todos los días a casa de una familia amiga, en una silla especial. Como no

(90) Melquiades Andrés, Historia de la mística de la Edad de Oro en España y América. Biblioteca de Autores Cristianos. Madrid, 1994, p. 239 y ss. Susan Juster, "Mistical Pregnancy and Holy Bleeding: Visionary Experience in Early Modern Britain and America", en The William and Mary Quarterly. 3rd Ser., Vol. 57, N 2 (Apr., 2000) pp. 254-255. Carolina Walker Bynum, op. cit., p. 209 y ss. En el caso francés el resurgimiento de la imitación de Cristo, al parecer, es un fenómeno que se desarrolla desde fines del siglo XVI. Ver Eric Suire, op. cit., p. 117 y ss.

(91) Éric Suire, op. cit., p. 225.

(92) Messía, op. cit., f. 142 v.

(93) Ibid., f. 174.

(94) Éric Suire, op. cit., p. 98.

(95) El historiador de la medicina Antonio Castillo-Ojugas estima que esos síntomas que experimentaba Urraca corresponden a una "atropatía psoriásica", ver "La reumatología en el Arte", Anales de la Real Academia Nacional de Medicina, $\mathrm{N}^{\circ} 102$ de 1985, p. 99. 
podía usar sus manos, era complemente dependiente de otros, al punto que debían darle de comer. Sin embargo, según refiere Messía, cuando lo llevaban al templo o la capilla para que dijese misa, sus molestias desaparecían y podía oficiar sin mayores dificultades. Todos estos padecimientos los recibía sin la menor queja y por el contrario, se mostraba agradecido de Dios por enviárselos. Ante una pregunta de su confesor por la intensidad de los dolores le habría contestado:

"Padre Maestro para honra y gloria de Dios son tan terribles (aunque no son los que merezco por mis culpas) que si no fuera con particular auxilio de Dios era imposible vivir con el menor de ellos, pero quiere S.M. Santísima hacerme este favor de que padezca por mis hermanos los pecadores y teniendo dolores en todas las partes de mi cuerpo, sin que haya una que descanse, son tan grandes los que me da Nro. Señor en las partes insensibles que son los cabellos y las uñas como me los pudiera dar en las niñas de los ojos" (96).

En la tradición hagiográfica europea se creía que cada santo recibía un don particular de Dios, que lo identificaba con el ejercicio de una sola virtud. Ello facilitaría la identificación de los fieles con un santo determinado, de quien, en su condición de intermediario, se esperarían beneficios precisos (97). En consecuencia, Messía, al relacionar de manera preferente la vida de Urraca con la virtud de la paciencia no hacía más que seguir aquella tradición. Sin embargo, ya en el siglo XVII se había ido imponiendo una teoría contraria, que asociaba la santidad a la práctica de todas las virtudes, lo que, por otra parte y según el parecer de la mayoría de los teólogos, no garantizaba alcanzar los altares, pues se requería el ejercicio heroico de ellas (98).

\section{- Los dones sobrenaturales}

Es en la exposición de estas gracias gratuitas o carismas, que eran vistas como los signos más evidentes de la santidad, en donde Messía puso el mayor énfasis, con lo que marcó al conjunto de la hagiografía, entregándonos una imagen del sujeto que escapa de la normalidad. A partir de la tipología desarrollada por Suire, es posible distinguir los milagros derivados de la oración; los milagros adivinatorios; los milagros de curación y los que modifican el orden natural (99). Pues bien, Urraca, según su hagiógrafo, gozó de todos esos diversos tipos de carismas. Consideraba a la oración como la llave para conseguir los favores divinos. Ya hemos visto que la practicaba permanentemente y al hacerlo entraba en contacto y mantenía diálogos con la Virgen, Cristo y Dios Padre; tenía visiones y experimentaba éxtasis. Messía dice refiriéndose a la oración: "En ella le inspiraba N. Señor todas las cosas que pretendía saber y muchas veces en ella le decía el Ángel de su Guarda las cosas por venir, así de los pecadores a quienes encomendaba a Dios como a los enfermos". Urraca hizo de la oración el centro de su vida y adquirió en su ejercicio una gran

(96) Fr. Francisco de Messía, op. cit., f. 173.

(97) Éric Suire, op cit., p. 209.

(98) Ibid., p. 211.

(99) Éric Suire, op cit., p. 205. 
sabiduría, transformándose en maestro de espíritu y como tal tuvo muchos discípulos, para los que escribió varios textos de meditación, de los que solo uno se ha conservado. Urraca fue un místico, que con facilidad llegaba al encuentro con Dios y caía en éxtasis. Messía dice que "no es posible haya guarismo para reducir a números los éxtasis y arrobos que tuvo; eran tan ordinarios que pocas veces se puso de noche en oración y de día que no se arrobase". A veces tuvo raptos tan intensos que su pulso se paraba y su cuerpo se helaba como nieve (100). Por esa característica de su espiritualidad y por las otras manifestaciones de su vida que refiere este autor, pareciera que Urraca no fue particularmente un hombre de acción; aunque se mencionan sus viajes para recabar limosnas y a veces adoctrinar indios y negros en obrajes, lo central de su religiosidad fue la oración y la dirección espiritual. Esto hace que nuestro personaje no cuadre con ese punto de vista historiográfico que divide a los santos desde una perspectiva de género, entre las mujeres como modelos de espiritualidad y sufrimiento y los hombres modelos de acción (101).

En el ámbito de los milagros adivinatorios, al decir de Suire, también cabía la posibilidad de tener visiones, las que se diferenciaban de las que se tenían en el transcurso de la oración porque no estaban asociadas a la contemplación. De ese tipo, Urraca experimentó frecuentes visiones de la Virgen, de su Ángel de la Guarda, del demonio, de San Pedro Nolasco, de la Santísima Trinidad y de la Cruz. Una visión que tuvo de la Cruz le impactó tanto, que la consideró como una especie de mandato divino; a partir de ahí comenzó a promover su devoción, dedicándose a repartir pequeñas cruces de madera que mandaba confeccionar. A la muerte de Urraca, según relata el hagiógrafo, muchas personas, religiosas y laicas, en forma individual y colectiva, tuvieron visiones de la cruz en el cielo. También gozó del don de la profecía, al que el hagiógrafo dedicó tres capítulos específicos, con más referencias en otras partes del texto. Nunca faltaban personas que lo iban a consultar sobre el futuro de pleitos pendientes, de lo acontecido con determinado navío, de enlaces matrimoniales y de personas ausentes; profetizaba la cercana muerte de personas y siempre sabía con antelación sobre qué le iban a consultar. El mismo Messía cuenta de situaciones que le ocurrieron a él con Urraca. Una de ellas fue el saber que estaba leyendo un libro que nunca le había comentado y en otro caso incluso decirle que al leer determinado apartado se había saltado un trozo y que lo volviera a ver, porque era importante. Este don fue uno de los que más fama le dio, lo que no deja de ser interesante, considerando que por lo menos en el reino de Nápoles de la Edad Moderna ese tipo de carismas estaba más bien asociado con la santidad femenina (102). Si al caso de Urraca se agregan los de otros venerables del

(100) Fr. Francisco Messía, op. cit., 175v.

(101) Caroline Walker Bynum, op. cit., pp. 24-26. Allan Greer, al estudiar el fenómeno hagiográfico en Nueva Francia, señala que ese modelo, con matices, sí se dio tanto en el caso de las mujeres como de los hombres santos de esos territorios, para el siglo XVII. Ver "Colonial Saints: Gender, Race, and Hagiography in New France", en William and Mary Quarterly, 3d Series, Volume LVII, Number 2, April 2000.

(102) Jean-Michel Sallmann, Nápoles et ses saints à l'âge baroque (1540-1750). Presses Universitaires de France. Paris, 1994, pp. 282-283. Donald Weinstein and Rudolph M. Bell también señalan que las visiones, como un tipo de don sobrenatural, eran más frecuentes en las mujeres santas de la cristiandad occidental, en Sanints \& Society. The Two Worlds of Western Christendom, 10001700. The University of Chicago Press. USA, 1982, pp. 228-229. 
Nuevo Mundo resulta que para estas tierras no es del todo claro hacer una distinción como la realizada para el sur de Italia (103).

Fr. Pedro también tenía dones taumatúrgicos. Curaba con la imposición de sus manos, al igual que su madre; además lo hacía a través del escapulario de la Virgen de la Merced y de las cruces que distribuía, las que ya antes de la muerte del Siervo de Dios tenían fama por sus propiedades curativas. Igualmente en este campo Messía cuenta su experiencia personal, que tuvo que ver con la mejoría de intensos dolores de cabeza. El hagiógrafo refiere varios casos de personas desahuciadas por los médicos a las que curó e incluye en el texto testimonios de algunos que tuvieron experiencias directas con Urraca en esa materia. Finalmente, en esta profusión de hechos extraordinarios tampoco faltó el don que le permitía modificar el orden natural. Messía señala que Urraca poseía el don de la bilocación. Muchas veces lo habrían visto en dos lugares al mismo tiempo y él presenta tres casos de los que "se han oído contar, dejando otros muchos que podía referir hasta que salgan con aprobación de la Iglesia en sus informaciones" (104).

En suma, esta hagiografía enfatiza los aspectos extraordinarios y maravillosos de la vida de Urraca y en relación con ello lo que más desarrollo alcanza es la narración relacionada con los dones gratuitos de que gozó, lo que viene a fortalecer la imagen de ser un sujeto elegido por Dios desde su nacimiento, en otras palabras el ser un predestinado. En cambio, el ejercicio heroico de las virtudes aparece un tanto disminuido en comparación con aquellas. Además, solo algunas son destacadas, como ocurre por ejemplo con la paciencia, que es a la que se le otorga más espacio. ¿Esta inclinación que tiene la hagiografía corresponde a un caso particular o se enmarca en una tendencia general de las hagiografías de la época? Todo parece indicar que ella se inserta en la orientación que el fenómeno tenía en amplios sectores del mundo católico del sur de Europa. Según Vauchez, desde fines de la Edad Media se había producido un cambio significativo en la valoración de la fama de santidad. Mientras la Santa Sede trataba de reconocer la práctica de las virtudes, las hagiografías ponían por delante los prodigios, con lo que el biografiado aparecía como un ser extraordinario (105). Suire, por su parte, refiriéndose al caso francés, dice que en la Época Moderna aquella situación no experimentará mayores cambios (106).

(103) René Millar Carvacho, "Santidad popular - santidad no oficial. Un lego de la Recoleta Franciscana de Santiago en el siglo XVII", Los franciscanos en Chile: Una Historia de 450 años. Academia Chilena de la Historia, edit. René Millar Carvacho y Horacio Aránguiz Donoso. Santiago, 2005, p. 60. Proceso de beatificación y canonización de san Pedro Claver. Edición de1696.Traducción de Anna María Splendiani y Tulio Aristizábal, S.J. Pontificia Universidad Javeriana. Universidad Católica del Táchira. Bogotá, 2002, pp. 381-396. Fr. Bernardo de Medina, Vida prodigiosa del Venerable Siervo de Dios Fr. Martín de Porres, op. cit., cap. XIII-XIV- XV-XVI y XVII. Un místico del siglo XVII. Autobiografía del Venerable padre Francisco del Castillo de la Compañía de Jesús. Publicada con Introducción y Notas por Rubén Vargas Ugarte, S.J. Lima 1980, cap. XXI-XXII y XIV

(104) Fr. Francisco Messía, op. cit., f. 157v.

(105) André Vauchez, La saintité en occident aux derniers siècles du Moyen Age. École française de Rome. Tercera edición. Roma, 1994, p. 615 y ss. En los siglos XII y XIII se producía una situación diferente, pues los autores de esa época idealizaban a las personas una vez que se borraba su recuerdo histórico. Los autores de las sucesivas versiones de las biografías iban agregando nuevos milagros, lo cual no ocurrirá a partir del siglo XIV, cuando nada más morir el santo era ya legendario. Jean-Claude Schmitt, "La fabrique de saints", en Annales. Économies. Sociétés. Civilisations. 39e Année - N² 2. Mars-Avril 1984, pp. 295-296.

(106) Éric Suire, op. cit., pp 209- 211. 
Pero, por parte, también es posible encontrar desde la segunda mitad del siglo XVI, sobre todo para el caso español, una fuerte desconfianza hacia las manifestaciones derivadas de la oración contemplativa, es decir de la mística (107). A raíz del fenómeno de los alumbrados, los éxtasis, las visiones, las levitaciones y otras expresiones extraordinarias, fueron vistas por las autoridades eclesiásticas como peligrosas y cayeron bajo sospecha de la Inquisición. Incluso personalidades que gozaban de esos dones, como Santa Teresa, escriben poniendo en guardia sobre las gracias místicas, pues podían ser obra del demonio (108). En esa coyuntura, pronto los jesuitas también adoptaron una actitud crítica hacia dichas formas de oración (109). En Francia las reservas de los hagiógrafos respecto de los carismas se detecta desde comienzos del siglo XVII (110). Además hay que considerar que la Santa Sede, en esa política de valoración de la práctica heroica de las virtudes, en el siglo XVII introduce limitaciones ya comentadas a la publicación de hagiografías, tratando de evitar el uso abusivo de la palabra santo y de que se atribuyera el carácter de milagro a acciones de personas no canonizadas o beatificadas (111). En consecuencia, la hagiografía de Messía se escribe en un momento de transición, en donde la tendencia iba más bien en sentido opuesto a la orientación que presenta aquella. Pero, por otra parte, es evidente que los cambios no son homogéneos, ni afectan a todas las regiones de manera simultánea. Pareciera que en América se reacciona más tardíamente a las políticas provenientes de la metrópoli y de Roma, lo cual además podía verse estimulado por la condición de criollo del autor (112), más permeable a las exageraciones del barroco americano.

(107) En el reino de Nápoles, desde el último tercio del siglo XVI, se aprecia una desconfianza hacia las expresiones místicas, ver Jean Michel Sallmann, op. cit., pp. 135 y 177 y ss.

(108) Teresa de Jesús, Moradas. Sextas, cap. 9. Vida. Cap. 25.

(109) Leszek Kolakowski, Cristianos sin Iglesia. La conciencia religiosa y el vínculo confesional en el siglo XVII. Taurus. Madrid, 1982, pp. 300-301.

(110) Éric Suire, op. cit., p. 195.

(111) Magnun Bullarium Romanun. SS Pontificum Urbani VIII. \& Innocentii X. Constituciones complectens. Editio Novísima. Tomus Quartus. Lugduni, 1692. Decretos de 30 de octubre 1625, de 5 de julio de 1634 y de 15 de julio de 1642, pp. 83-84; 196-198 y 229-232. También, Jean-Robert Armogathe " La fabrique des saints. Causes espagnoles et procédures romaines d'Urbain VIII à Benoit XIV (XVIIe-XVIIIe siècles), en Mélanges de la Casa de Velásquez. Nouvelle Série. Tome 33 (2), Casa de Velásquez, 2003, p. 17 y ss. La política de la Santa Sede respecto a la santidad, con Urbano VIII, buscaba controlar la piedad popular, evitando el desarrollo de creencias supersticiosas, ver Pierre Delooz, "La canonización de los santos y su significación social", en Concilium. Revista Internacional de Teología. Nº 149. Madrid, 1979.

(112) En la segunda mitad del siglo XVII, otro autor criollo, José Buendía, escribe una hagiografía en que lo extraordinario también es determinante: Vida admirable y prodigiosas virtudes del venerable y apostólico padre Francisco del Castillo. De la Compañía de Jesús. Natural de Lima, ciudad de los Reyes de la Provincia del Perú. Madrid, por Antonio Román, 1693. Con todo, también podemos encontrar hagiografías sobre hombres virtuosos en el Perú del siglo XVII en que se hace presente que la santidad no es solo el hacer milagros, sino también el ejercicio de las virtudes y de las mortificaciones. En esos términos se expresa Fr. Alonso Manrique de Zúñiga en Retrato de perfección cristiana: portentos de la gracia y maravillas de la caridad en las Vidas de los Venerables P. Fr. Vicente Bernedo, Fray Juan Macías religioso converso y Fray Martín de Porres. Venecia, 1696. Ver Andrés Estefane Jaramillo, "Santos terrestres y santos celestes. El fenómeno de la santidad a través de la hagiografía. Perú, siglo XVII". Mapocho, $\mathrm{N}^{\circ}$ 53, primer semestre 2003, pp. 97-99. En México también se daría un tipo de hagiografía con fuerte énfasis en lo extraordinario y maravilloso, ver Serge Gruzinski - Jean-Michel Sallamann, op. cit., p. 796 y 803-804. También, Antonio García Rubial, op. cit., p. 74. 
- $\quad$ La influencia en la causa de beatificación

La obra de Messía buscaba hacer propaganda al Siervo de Dios, hacerlo popular; que aquellos que no lo habían conocido supieran a partir de su lectura de los méritos que lo habían adornado y de cómo, gracias a las virtudes que había practicado y los dones recibidos era un digno intercesor ante Dios. Pero de manera más específica, el autor buscaba, como hemos señalado, que se activara lo antes posible el proceso informativo. Esperaba que su obra estimulara a los fieles a pedir la apertura de la causa. Messía no cerró de manera definitiva su obra. La dejó abierta para ir agregándole nuevas pruebas de santidad en la medida que los fieles le fueran entregando testimonios de experiencias y de milagros que recibieron gracias a la intercesión del Siervo de Dios. De hecho prometió hacer una nueva obra mucho más completa, que no fuese un simple epítome. Preparó con detalle el manuscrito para su publicación. Obtuvo todas las autorizaciones que se exigían para ello y fue más allá porque buscó el apoyo de personas influyentes del virreinato. Pero mientras se concretaba su entrada en las prensas, se sacaron numerosas copias que tuvieron amplia circulación en Lima. Al mismo tiempo enviaba ejemplares a Madrid, a las autoridades políticas, a personas influyentes y a la Orden de la Merced.

Es evidente que Messía logró los objetivos que perseguía y la obra le fue de gran utilidad. En su calidad de autor-confesor se transformó en el agente principal pro apertura del proceso. De hecho consiguió que se abrieran informaciones específicas sobre algunos milagros que habían tenido lugar después de la muerte del Siervo de Dios, cuyas referencias alcanzó a recoger en su obra. También, del propio texto se desprende que las autoridades eclesiásticas efectuaron algunas informaciones para probar su santidad, que no pasaron más allá, posiblemente por no atenerse a las formalidades que se exigían para estos casos. Entretanto, Messía no paraba en sus afanes, buscando los apoyos necesarios para la apertura formal de la causa y, en ese sentido, la circulación de su obra fue un medio eficaz para crear conciencia al respecto, más todavía cuando pasaba el tiempo y el recuerdo de Urraca podía diluirse. Finalmente, las autoridades provinciales de la Orden lograron que en 1671 se iniciara el proceso ordinario con miras a la beatificación. Habían pasado 14 años desde su muerte y en ese tiempo la obra de Messía había circulado profusamente entre ciertos grupos de fieles limeños.

Como en todo proceso de este tipo, el procurador de la orden, al hacer la petición para que se abriera causa de beatificación, acompañaba a las autoridades diocesanas una lista con las preguntas a las debían ser sometidos los testigos, que en este caso eran 23. Lo más probable es que hayan sido elaboradas por el propio Messía, aparte de que reflejan bastante bien el contenido de la hagiografía, por lo que desde su base el proceso estará condicionado por la imagen y la orientación que aquella muestra de Urraca. Pero todavía más. Ya en el proceso apostólico, el Promotor de la Fe hace presente que varios testigos habían declarado que conocían de los sucesos sobre que se les preguntaba por la lectura de la obra de Messía. Es decir, la hagiografía no solo pudo haber influido en el cuestionario sino que también, y de manera evidente, en las respuestas, por lo que el conjunto de la causa terminó siguiendo el tenor de aquella. 


\section{B. Las otras obras y sus perspectivas}

\section{- $\quad$ Los matices de Colombo}

Dada que la fuente básica que utiliza Colombo es la obra de Messía, el contenido y la orientación de El Job de la Ley de la Gracia está muy condicionado por esta última. Desde ya el título de la obra lo toma de un comentario que aquel efectúa a propósito de la virtud de la paciencia en Urraca. Además repite el mismo orden de exposición de aquella y con frecuencia reproduce textualmente a Messía, a veces reconociéndolo, aunque la mayoría de las veces no. Los capítulos que refieren la biografía en su desarrollo cronológico siguen el mismo orden de la obra del confesor y en algunos casos repite de manera idéntica el título de los mismos (113). Todavía más, el contenido de ellos es por lo general la reiteración de los mismos acontecimientos narrados por Messía. En ese sentido se puede decir que agrega muy poco a lo ya expuesto por el confesor. Los temas nuevos que incorpora tienen que ver con la etapa que, ya siendo religioso, pasa en España, en la medida que pudo disponer de algún material que se encontraba en el convento de Madrid. En todo caso es información muy menor y tiene que ver más que nada con la mención de los religiosos que vivieron en ese tiempo en el aquel convento (de los que entrega algunos datos biográficos) y que habrían sido discípulos de Fr. Juan Falconi y del propio Urraca en el ámbito de la oración mental (114). También agrega algo a la labor pastoral que desarrolló Urraca en la corte madrileña y da algunos detalles nuevos relacionados con su regreso a Lima. En todo caso, Colombo, en la parte final de su obra, rompe con la secuencia de los capítulos desarrollados por Messía, alterando de manera importante la estructura original. En cierta medida lo hace por razones de lógica. La obra de Messía, en sus últimos capítulos no mantiene la sucesión cronológica y se desordena al introducir testimonios personales, tanto del propio autor, como de discípulos y conocidos de Urraca; también incorpora un escrito propio al que denomina testamento espiritual, junto a una copia del librito de espiritualidad del Siervo de Dios. Da la sensación que Messía concluyó su obra de manera acelerada y agregó diversos testimonios con declaraciones de fieles que daban a conocer hechos extraordinarios que les sucedieron por mediación de Urraca, en vida o después de muerto (115). Tenía apuro por enviar su obra a la península para que se imprimiera y estimulara la apertura de la causa (116).

Colombo, ante esas características que presentaba la última etapa de su modelo, optó por seguir con una organización muy similar a las fases iniciales, para lo cual sacó ideas y acontecimientos de diferentes capítulos del libro de Messía y los

(113) Esto ocurre por ejemplo en el capítulo IV, titulado: "De cómo le dieron el hábito en el Convento de Quito, las ejemplares virtudes en que floreció en su Noviciado, los favores que recibió de la Virgen y las persecuciones del demonio". También en el V que lleva por título: "Prosíguense sus virtudes y otros sucesos raros de su Noviciado".

(114) Fr. Felipe Colombo, op. cit., pp. 192-193.

(115) Esta situación afecta a la obra en diversos capítulos, a partir del especialmente del 29.

(116) En tales apuros, el hacer calzar el envío a España con la salida de los navíos era un tema no menor, que influía en la prolijidad con que terminaba elaborándose la documentación que se enviaba a la metrópoli. 
agrupó en función de alguna materia o tratando de respetar la secuencia cronológica. Otras modificaciones obedecieron a la idea, ya comentada, de enaltecer a la orden de la Merced, que en la obra de Messía se la resaltaba más bien de manera indirecta, en cuanto se recalcaba la relación de Urraca con la Orden y con su modelo de santidad, San Pedro Nolasco. Colombo trató de insertar al personaje en el contexto de la labor apostólica y política desarrollada por la Orden en América (117). Pero, algunos de los cambios importantes que introduce Colombo responden a otros criterios más de fondo. Debe recordarse que esta obra se publicó en 1674 cuando acababa de terminarse en Lima el proceso ordinario por la beatificación del Siervo de Dios y debían iniciarse las gestiones para que se autorizara la realización del proceso apostólico. El Job de la Ley de Gracia debía contribuir al éxito de tales trámites o por lo menos no ser factor negativo al respecto. A partir de esos criterios Colombo hará todo lo posible por justificar algunos comportamientos del Siervo de Dios que podían ser controvertidos.

Al respecto, uno de los temas que podía despertar críticas era el cumplimiento con el cuarto voto de la Orden: el de la redención de cautivos. Nuestro autor enfatiza mucho más que Messía las justificaciones por no haber ido a tierras de infieles a rescatar cristianos prisioneros. En el primer párrafo en que toca el tema señala una de las explicaciones recurrentes: "Y en voto de redimir cautivos tuvo siempre deseos ardentísimos de cumplirle y poner su vida porque se salvasen, haciendo todos los días oración particular por ellos, no dejando pasar ocasión de solicitar limosnas para su redención, siendo muchas las que juntó y se dieron por su medio" (118). En los capítulos que ambos autores dedican al tema, Colombo lo desarrolla más, incorporando información sobre el sentido del mismo y sobre la labor que en ese campo habían realizado las provincias peninsulares de la Orden. También agrega el texto de una oración que rezaba Urraca todos los días por los cautivos. Y específica que uno de los objetivos que perseguía con su viaje a España era encontrar la ocasión para ir a alguna redención y cumplir con ello el cuarto voto, que tanto anhelaba (119). Otra de las cuestiones que podían resultar controvertidas fue la cercanía de Urraca con las esferas de poder. También aquí Colombo, sin agregar mayor cosa, enfatiza las explicaciones que ya estaban en Messía. Este autor refiere que el Siervo de Dios siendo muy joven, en su viaje a Lima, antes de su ordenación sacerdotal, se cruzó de manera providencial con el virrey Montesclaro, que venía a sumir el cargo, generándose una relación que lo transformó en uno de los capellanes de palacio. Luego tendrá un estrecho vínculo con el virrey Príncipe de Esquilache y su esposa, de quienes fue director espiritual. La relación alcanzó tal fuerza que, una vez cumplido su período, el virrey logró que Urraca lo acompañara de regreso a España. Allí se conectó con los más altos círculos de la corte, constituyéndose en padre espiritual de numerosas señoras principales y de la misma reina. Para Messía, todo era resultado de la providencia y del cumplimiento estricto de la obediencia por parte del Siervo de Dios. En suma, él asistiría regularmente a palacio a guiar espiritualmente a las

(117) No solo cantó las glorias del convento de Lima, sino que hizo lo propio con el de Quito, cuando en el tomó los hábitos. Fr. Felipe Colombo, op. cit., p. 158 y ss.

(118) Fr. Felipe Colombo, op. cit., p. 167.

(119) Ibid., p. 194. 
autoridades por petición expresa de estas a los prelados de Urraca, los que lo enviaban bajo mandato de obediencia. Colombo no cambia la argumentación, pero recalca el tema de la obediencia. Por ejemplo, este autor presenta el viaje a España como resultado de una intervención divina, de la que el Príncipe de Esquilache y su esposa, fueron un medio, al igual que los prelados que lo autorizaron (120). En cuanto al vínculo con este virrey, Colombo lo presenta destacando la muy buena acogida que tuvo al llegar a Lima, en gran medida por venir acompañado del padre Urraca, es decir por hacer lo que David mencionaba en el Salmo 5 en cuanto a que el Señor no acoge a los malvados; de donde infiere que el Príncipe, asistido de los buenos, conquista la inclinación de los vasallos (121). Sintetiza su justificación respecto de la cercanía de Urraca con las autoridades políticas con las siguientes palabras: "Tiene Dios singular cuidado de que haya siervos suyos, que comuniquen con los seculares, que se entren por las Cortes y Palacios, donde suele haber mayor necesidad" (122).

Por último, Colombo trata de matizar por lo menos en algo la excesiva preeminencia que tenía lo maravilloso en la obra de Messía. Está muy lejos de su intención el pretender disminuirla de manera radical. No podemos olvidar que aquella obra es el soporte de la suya y por lo mismo también termina impregnada de esa orientación. Sin embargo, sacará algunos acontecimientos o planteará sus dudas respecto de otros. Ante determinadas situaciones inserta lo experimentado por Urraca en una explicación que incluye a otros santos que vivieron situaciones similares. Una exposición de ese tipo hace a propósito del conocimiento que tuvo Urraca, estando postrado en cama, de la muerte de un religioso de la Compañía de Jesús en el momento en que acontecía (123). Colombo incluye en su texto numerosos relatos de visiones y profecías, sacados de Messía por cierto; pero también deja varios otros fuera, como una visión que tuvo Urraca de una imagen de Cristo con muchos resplandores, otra de Santa Ana y algunas que mostraban al niño Jesús desnudo (124). Al referir el caso de las bilocaciones, Colombo explicita su punto de vista. Dice sobre el particular que, dado que el título que le puso al capítulo Messía iba contra sentencia de Santo Tomás, "templamos el título: no sea que nos censuren" y agrega haber "ajustado los sucesos de este capítulo a menor milagro; dejando al vario sentir de probables opiniones si estas apariciones fueron en cuerpo fantástico o si duplicó Dios milagrosamente su presencia" (125).

Es evidente que Colombo no tuvo éxito en su objetivo de favorecer la causa de Urraca, posiblemente no por responsabilidad directa de su obra, sino porque en definitiva no fue capaz de contrarrestar ese excesivo predominio de lo milagroso en la vida del postulante, que terminó condicionando los cuestionarios del proceso y las respuestas de los testigos. A comienzos del siglo XIX la postulación no llegó a buen término y entre las animadversiones que expuso el Promotor de la Fe estuvieron

(120) Ibid., p. 191.

(121) Ibid., p. 189.

(122) Ibid., p. 187.

(123) Ibid., p. 213.

(124) Fr. Francisco Messía, fs. 155-156.

(125) Fr. Felipe Colombo, op. cit., p. 215. 
algunas visiones y profecías atribuidas al Siervo de Dios (126) y en el decreto que dictó la Sagrada Congregación de los Ritos la causa fue suspendida, lo que implicaba que no se había probado el ejercicio heroico de las virtudes (127).

No quisiéramos concluir este apartado de Colombo sin tocar un punto que los estudios hagiográficos han resaltado cuando se trata de vidas de santos del Nuevo Mundo. Para diversos autores esas hagiografías reflejarían una valoración de la identidad criolla por parte de los hagiógrafos. En este sentido las obras más importantes que se han escrito son la de Antonio Rubial García y la de Ronald J. Morgan, que tienen ese tema como hipótesis central (128). En los dos autores que hemos analizado hasta ahora esa cuestión está de alguna manera presente, pero no así en los dos restantes, en quienes no aparece. El asunto inquieta moderadamente solo a los autores del siglo XVII y lo enfrentan de manera distinta, lo cual es lógico dada la naturaleza diferente de uno y otro: Messía era criollo y Colombo peninsular. A eso se agrega otro elemento que hace más complejo el fenómeno. Urraca había nacido en la península, pero su vida religiosa, su fama de santidad y muerte gloriosa acontecieron en el Nuevo Mundo.

Francisco Messía no destaca mayormente el significado nacional que pudo tener para Perú la figura del padre Urraca, aunque algo dice al respecto. En la parte final hace mención a la ciudad de Lima, como aquella que pregonó las glorias del Siervo de Dios y lo aclamó como santo "con el mayor concurso que se ha visto". Considera que se ha producido una relación especial entre ambos. Urraca la quiso y le brindó su protección, como lo hizo con unos temblores que se produjeron en esa época; y ante unos rumores que circularon de que la ciudad se iba a hundir, habría dicho: "No mis padres, que Lima entre todas las ciudades del mundo es la niña de los ojos de Dios". Por su parte, Messía esperaba que la ciudad nombrara a Urraca como patrono y celebrara por lo alto su futura canonización. En consecuencia, vemos que dicho autor, más que promover el orgullo patrio a través de la figura de Urraca, lo que hace es destacar el vínculo de él con la ciudad y a partir de ahí valorar de manera indirecta el ámbito local urbano, en una postura relativamente similar a la que según García Rubial se da con varios venerables de México en el siglo XVII (129). Con todo, una situación diferente ocurre con los informantes y garantes de la obra, algunos de los cuales sí presentan a Urraca en relación con el mundo americano y como fruto de estas tierras. Por tanto, lo que hacen es destacar, a través de su persona, las riquezas del Nuevo Mundo, en una exaltación orgullosa de lo que espiritualmente podía surgir en él, digno de ser admirado en Europa y en toda la Iglesia. Uno de estos informantes esperaba la pronta publicación de la obra para que "se sepa en toda Europa que en nuestra América y reinos del Perú no solo

(126) Summarium Objectionale, en Positio Super Virtutibus, op. cit.

(127) Decreto de la Sagrada Congregación de los Ritos de 7 de julio de 1807, en Archivo de la Congregación de los Santos. Decreta 1805-1810, fol. 527.

(128) Antonio Rubial García, La santidad controvertida. Hagiografía y conciencia criolla alrededor de los venerables no canonizados de Nueva España. Fondo de Cultura Económica, México, 1999. Ronald J. Morgan, op. cit.

(129) Antonio García Rubial, op. cit., pp. 80-81. La relación entre hagiografía e identidad y local es un fenómeno que también se dio en Europa, como lo destaca para Sicilia Sara Cabibbo, Il Paradiso del Magnifico Regno. Agiografi, santi e culti nella Sicilia spagnola. Viella editrice. Roma, 1996. 
hay plata a millones en cerros de Potosí, ni tan solamente oro a quintales en Carabayas y Aporamas, sino varones santos, apostólicos y milagrosos en las religiones mendicantes, que introdujeron la fe" (130). En términos muy similares se expresa el Dr. Andrés de Villela, el oidor más antiguo de la Real Audiencia, para quien esta obra impresa contribuirá a la gloria de todo el Perú, que es una tierra especialmente favorecida por Dios pues no solo le ha regalado riquezas mineras sino también "ilustres religiones y heroicos sujetos" (131).

Felipe Colombo, por su parte, fue muy cuidadoso a la hora de enfocar el tema de la identidad nacional. Buscaba destacar el significado para Urraca de la patria originaria, enfatizando el vínculo que siempre mantuvo con España, pero sin tratar de opacar la relación de aquel con el Nuevo Mundo. El autor deja muy en claro que el Siervo de Dios es hijo de aquellas tierras, a las que siempre guardó especial cariño, como lo dejó en evidencia durante el período que pasó allí, entre 1623 y 1628, al crear en Burgos y Jadraque unas buenas memorias y otras fundaciones. Al decir de este autor, Urraca habría actuado como Cristo, que no se olvidó de su patria Nazareth, al otorgarle mercedes a sus hijos (132). España se podía sentir orgullosa de haberle dado a Perú esta joya, de cuyas virtudes disfrutó Lima, la que por lo mismo lo aclamó a su muerte y es la pregonera de sus glorias. En el florido estilo que lo caracteriza, Colombo utiliza la siguiente metáfora para referir el significado de la muerte de Urraca: "Púsose el sol de la religión en aquella provincia, apagase aquella luz española, que ardió en el Nuevo Mundo" (133). El autor, no obstante su condición de peninsular, resalta la importancia de América en el mundo, haciendo notar las riquezas y bondades de los reinos del Perú. A Lima la señala como "cabeza de la Monarquía Española en aquel nuevo mundo, en quien se hayan cuantas cualidades [naturales y espirituales] pueden causar grandeza a una república... [por lo que] puede competir con cuantas ciudades tiene Europa" (134). En esa ciudad, la Orden de la Merced había realizado una labor política y religiosa extraordinaria y había hecho posible la existencia de personas de excepción entre las cuales sobresalía Urraca.

Los dos autores aprovechan sus obras para transmitir "al mundo" que el Perú no solo era valioso por sus riquezas naturales sino por los frutos espirituales que allí podían darse. Para los informantes de la obra de Messía, Urraca contribuye a la gloria del Perú. Gracias a él dicha tierra sería conocida y valorada desde otra perspectiva y no solo desde el punto de vista de la riqueza material que aportaba al Imperio. Había en esas expresiones un claro orgullo nacional o para ser más preciso de amor al terruño, reflejado en esa espera por una valoración externa. Colombo, a su vez, intenta una síntesis. España le dio el ser a Urraca y lo introdujo en la fe. América y Perú lo vieron germinar en su santidad y se beneficiaron de los dones y

(130) Francisco Messía, op. cit., f., 29. Otro de los informantes, el catedrático de Instituta de la Universidad, Gregorio de Rojas, califica a Urraca, como "varón tan prodigioso, honor de este Mundo Nuevo y envidia del antiguo", op. cit., f. 57v.

(131) Ibid., f. 64v. Sobre los santos peruanos como expresión del triunfo del cristianismo sobre la idolatría y del éxito de la evangelización, ver Andrés Estefane Jaramillo, op . cit., pp. 75-80.

(132) Felipe Colombo, op. cit., p. 191

(133) Ibid., p. 252.

(134) Ibid., p. 279. 
maravillas que Dios obró a través suyo. Ambos lugares podían congratularse de haber acogido ese ser extraordinario.

\section{- $\quad$ La reorientación de la Vita anónima}

La "Vida" del autor anónimo, por su parte, presenta varias peculiaridades con respecto a las dos hagiografías anteriores. Como ya dijimos, debe haber sido escrita después de la publicación de la Positio de 1807 y posiblemente entre las Congregaciones de 1816 y 1821, cuyas resoluciones fueron negativas para la causa. Esta suposición se fundamenta en el conocimiento que tuvo el autor del contenido de la Positio, de la que saca declaraciones de testigos del proceso. Pero ¿por qué podemos ser tan precisos para aventurar una fecha posible de elaboración? Pensamos que la obra fue escrita por encargo, para ser presentada a la segunda Congregación que estudiaba la causa, como un elemento más en el alegato que intentaba modificar la resolución que poco antes había negado la probanza de las virtudes de Urraca. Basamos esto último en la orientación que presenta la obra, que a diferencia de las otras, pone el acento en las virtudes del postulante. No podemos olvidar que la "Vida" de Messía dejaba en segundo plano a las gracias santificantes, privilegiando los dones sobrenaturales y por ende los hechos maravillosos. Desde el siglo XVII la Santa Sede y numerosos teólogos tendieron a valorar cada vez más el ejercicio heroico de las virtudes, expresando que las gracias gratuitas no eran indispensables para el reconocimiento de aquellas, como lo expuso Prospero Lambertini, futuro Benedicto XIV, en 1734 (135). Las causas de beatificación y canonización tendieron también a centrarse en las pruebas que demostraban que el candidato había ejercido de manera heroica todas las virtudes, sin dejar de lado la verificación del goce de los dones sobrenaturales, por cierto. El autor anónimo lo que busca es resaltar la relación del Siervo de Dios con las gracias santificantes.

Toda la tercera y última parte del libro la dedica específicamente a las virtudes del padre Urraca; pero todavía más, en las partes anteriores también hace constantes referencias a ellas y relaciona la narración de los hechos en que interviene con la virtud correspondiente. En relación con las otras hagiografías incorpora comentarios y explicaciones sobre la base de los textos sagrados y de opiniones vertidas por padres de la Iglesia, como San Jerónimo, San Basilio o San Bernardo. A veces trataba de dar una fundamentación teológica al comportamiento del sujeto y a los hechos que le ocurrían y en otras más bien reflexionaba sobre el punto, citando autores o la Biblia. Por ejemplo, en el capítulo sobre el ingreso de Urraca al noviciado se detuvo en destacar lo que había implicado para él la toma del hábito y la decisión de vivir en comunidad; a partir de ahí, se refiere, siguiendo a San Jerónimo, a las ventajas para el espíritu de vivir en comunidad, pues ayudaba a la práctica de las virtudes de la humildad, de la paciencia, del silencio y de la mansedumbre (136). Siguiendo con la descripción de su etapa en el noviciado toca el tema de las mortificaciones, pero antes de narrar las incidencias con los cilicios, da una explicación acerca del sentido de la penitencia como virtud. La considera un verdadero magiste-

(135) Éric Suire, op. cit., p. 234.

(136) Vita del Ven. Servo di Dio... op. cit., p. 30. 
rio, que da el fundamento y la forma a toda perfección, en cualquier género de virtud: la mortificación interior en relación con los afectos y la exterior, con los sentidos (137). Y agrega, que si bien el joven Urraca no tenía en su interior cosa alguna que vencer siempre se afligía por el mundo, que crucificó a Cristo. Ante lo cual, al decir de nuestro autor, seguía las palabras de San Pablo: "El mundo ha sido crucificado para mí" (138). Más adelante, en la tercera parte, en donde trata de las virtudes, vuelve a hablar de la penitencia, relacionándola con la oración. Dice que esta y el ayuno son "cosa buena", entendiendo por este último, de acuerdo con la Biblia, cada suerte de penitencia y mortificación. Ambos serían medios necesarios para el beneficio espiritual del alma y estarían correlacionados: se debía pedir ayuda, orar, mortificarse y vigilar poniendo freno a las pasiones (139). El autor, tal vez para contrarrestar las abundantes referencias que al respecto existían sobre Urraca, se preocupa, como principio, de disminuir el valor de las rigurosas disciplinas, de aquellas que extenuaban el cuerpo con ayunos o laceraban las carnes con frecuentes disciplinas o cilicios. A su juicio, el verdadero fundamento de la virtud sólida no estaría allí, sino en la mortificación interna del hombre, es decir en la represión de las pasiones (la ira, la concupiscencia y el orgullo) y de otros enemigos del alma, de modo que siempre debía frenarse y abatirse la voluntad propia para seguir la de Dios (140). El hagiógrafo intenta decirnos que Urraca fue más virtuoso por el control interno de las pasiones que por el uso de los cilicios.

Embebido de estas máximas, según el hagiógrafo, Urraca comenzó a prepararse para su profesión religiosa ejercitándose mayormente en la práctica de cada virtud. Y para mayor perfección, de la ya adquirida, y avanzar diariamente, aprendía de la vida de los santos. En ese sentido, el ejemplo más adecuado que encontró fue el de San Pedro Nolasco porque para él tenía singulares ventajas. La vida de los otros santos sería para Fr. Pedro un mero ejemplo e incitación a la virtud. La del fundador, era además un mandamiento de padre (141). Como se puede apreciar, el autor anónimo siempre intenta alguna explicación al actuar de Urraca, sin conformarse con repetir determinados acontecimientos. Sobre el particular, otro caso que podemos citar corresponde a la valoración de la labor que desarrolló en la corte de Madrid. Al respecto señala que allí realizó con la "esclavitud del pecado" que embargaba a los señores de la corte, lo que no pudo hacer en África con los esclavos (142). A propósito del relato de algunas visiones de la cruz que tuvo Urraca, el autor expresaba que ellas debían considerarse como manifestaciones de la misericordia y omnipotencia divina, que las permitía para contribuir a la exaltación del misterio de la redención, a la humillación de sus enemigos y a la gloria del Redentor. Además agregaba que a través de la historia eran muchos los hombres que habían experimentado ese tipo de visiones (143). En la parte dedicada a las virtudes, no deja ninguna

(137) Ibid., p. 36.

(138) Ibid., p. 37. Carta de San Pablo a los Galatas, 6-14

(139) Vita...op. cit., p. 235.

(140) Ibid., pp. 90-91

(141) Ibid., p. 46

(142) Ibid., p. 141.

(143) Ibid., pp. 154-155. 
sin analizar y muestra aquellos hechos que reflejaban que Urraca las practicó heroicamente. Al respecto y solo deteniéndonos en la caridad, argumenta que respecto del prójimo la ejercitaba procurando la salvación de su alma y que lo hacía por medio de la oración, el confesionario, el consejo y la mortificación.

No obstante todos los matices y explicaciones que el hagiógrafo da de la vida de Urraca, está consciente de que se trata de un ser extraordinario porque gozó de dones sobrenaturales, pero también y especialmente porque practicó en forma heroica todas las gracias santificantes. Por lo mismo, a propósito de la forma como observó los votos de la Orden, señala: "Dios tal vez hizo comparecer en el mundo al Siervo de Dios más bien como monumento de su omnipotencia, que como modelo y ejemplo a imitarse" (144).

El intento de esta Vita por cambiar el destino del proceso fue infructuoso, pues la Congregazione dei Riti volvió a dictar una resolución negativa sobre la causa. Como consecuencia de ese fallo adverso y otras circunstancias, el proceso permaneció suspendido por muchos años, hasta que gracias a una solicitud fundamentada de los procuradores de la Orden fue reabierto en 1954, debiendo iniciarse una nueva postulación.

\section{- La moderna biografía de Aquatías}

En el marco de esa reactivación del proceso se inscribe esta hagiografía, publicada en 1974 y que responde a criterios sustancialmente diferentes a todas las anteriores. Su autor, que en ese momento era el postulador de la causa, acogió las recomendaciones de la Congregación de las Causas de los Santos en cuanto a escribir una biografía "que fuese descarnada de lo extraordinario, de lo que tuviese visos de maravilloso, milagroso, sobrenatural, cosas incompatibles con el ordinario vivir humano" (145). La idea era que se presentara una imagen de Urraca como un hombre natural, que había sabido superar numerosas y dolorosas pruebas, merced a su entrega a Cristo y su compromiso con la pasión y con el sacrificio en la cruz.

El resultado fue una obra en la que se prescindía de cualquier descripción de hechos extraordinarios y se eludía toda explicación que no fuese lógica y razonable. En aquellos acontecimientos en donde Messía hacía intervenir a la Virgen o al demonio como actores decisivos, ese protagonismo era omitido o se señalaba que el Siervo de Dios atribuía el desenlace favorable a la acción de la Virgen. Tales explicaciones eran dadas, por ejemplo, al referir los incidentes que lo salvaron de morir ahogado al intentar embarcarse hacia América y el saber después que el barco en que debía venir se hundió pereciendo todos los pasajeros. Numerosos son los acontecimientos que tienen aclaraciones de ese tipo. Aquatías tiene extremo cuidado en no mencionar hechos maravillosos, no obstante que las fuentes que utiliza son mayoritariamente el Epítome de Messía y las declaraciones del mismo en la causa de beatificación, que obviamente abundaban en referencias de aquel tipo.

(144) Ibid., 224c.

(145) P. Luigi Aquatías, Vida ...op. cit., p. 9. 
No obstante que la estructura de la obra, como señalamos, privilegia la narración cronológica, incorpora en algunas partes determinados capítulos que tienen un carácter temático. A través de esa fórmula refiere la labor que desarrolló el Siervo de Dios en ciertas materias, como la devoción Mariana, la actividad apostólica y social y sobre todo el de la práctica de las virtudes. Por ejemplo, en el tema de la caridad con los más necesitados destaca que no solo se preocupó del auxilio material a los pobres, sino que también buscó entregarles algo que trascendiera y los inclinara a la piedad. Por lo mismo su caridad tendría "un fin sobre todo espiritual; procuraba ganar los corazones a Dios, procuraba con toda su capacidad que estos no ofendiesen a Dios" (146). Otras virtudes a las que dedica mayor atención corresponden a la paciencia y la penitencia, cuyas duras prácticas las justifica con las palabras que, según Messía, habría expresado el propio Urraca para referirse a una de las mortificaciones a que se sometía: "Este cilicio y cuanto yo soporto es por los pecadores" (147). El tratamiento que le dio a los dones sobrenaturales fue muy cuidadoso y de hecho hizo más bien una mención indirecta a propósito de la estadía de 40 días que tuvo al final de su vida en casa de uno de sus hijos espirituales, donde lo sorprendió una enfermedad que lo obligó a convalecer allí. Durante ese período lo fue a visitar mucha gente para pedirle favores, como resultado de lo cual se habrían sucedido hechos milagrosos, que el autor no describe, aunque señala que el confesor de Urraca, es decir Messía, decidió mencionar algunas "para que se dé gloria a Dios". Cierra la cuestión expresando que esos días que permaneció en casa de la familia amiga se habían prestado para numerosos dificultades de la causa (148).

La publicación de esta Vida de Urraca hay que verla en el contexto de los cambios que experimentó durante el siglo XX el procedimiento en las causas de los santos, que tendió a simplificar las causas históricas (149). El replanteamiento de la causa de Urraca, hagiografía incluida, a partir de aquellas modificaciones en los procedimientos, más la nueva política en materia de canonizaciones del Papa Juan Pablo II, explican el decreto pontificio de enero de 1981 que finalmente aprobó el ejercicio heroico de las virtudes del candidato. Esto implicaba que Urraca era considerado Venerable y su futura beatificación iba a depender de que se aprobara, por las instancias médicas y teológicas establecidas, la ocurrencia de un milagro merced a su intercesión.

\section{REFLEXIONES FINALES}

De este análisis de las diferentes hagiografías que se escribieron sobre el Venerable Fr. Pedro de Urraca quedan en evidencia algunos aspectos muy significativos. De las cuatro comentadas, la que consideramos más interesante es la de Fr. Francis-

(146) Ibid., p. 110.

(147) Ibid., p. 126.

(148) Ibid., pp. 137-141.

(149) Fabijan Veraja, Le cause di canonizzazione dei santi. Librería Editrice Vaticana. Cittá del Vaticano, 1992, p. 13 y 14. Motu proprio de 6 de febrero de 1930 sobre la constitución de una sección histórica en la Congregación de los Ritos y Normas de 4 de enero de 1939 sobre la construcción de los procesos ordinarios en las causas históricas, ambas disposiciones del Papa Pío XI. 
co de Messía por la gran influencia que tuvo en el proceso de beatificación del Siervo de Dios. Pero también por otros factores, derivados de su condición de confesor y criollo, que de alguna manera se reflejan en la obra. Al respecto es interesante apreciar que su intervención va más allá que la del simple autor que presenta la vida del protagonista, pues se involucra en la obra de tal manera que en determinadas partes aparece como un actor secundario de la misma. En ese sentido se daría un fenómeno parecido al que ocurre con las "Vidas" de mujeres escritas por sus confesores, los que se integran al relato de la biografía, eso sí, con bastante más protagonismo que el asumido por Messía en su obra.

La condición de criollo del autor se manifiesta en la obra, no con intensidad, pero lo suficiente para hacer presente una identificación entre Lima y el Siervo de Dios. La ciudad lo ha reconocido y lo aclama como santo y él la protege con sus oraciones y proclama que es la niña de los ojos de Dios, por lo que nada le puede pasar. Pero la obra de Messía refleja por una vía indirecta la valoración del elemento criollo asociado al personaje, no obstante que tenía la peculiaridad de ser originario de la península. Fueron algunos de los autores de los informes y de las censuras los que expresaron de manera más determinante el significado del Siervo de Dios para el ámbito americano. La gloria suya implicaba también la del Perú. Porque aquí se había forjado este tesoro, al igual que la plata de Potosí y el oro de Carabayas. La publicación de la obra iba a permitir a Europa y a todo mundo católico se supiera que en estas tierras la religión estaba arraigada y tenía tanta fortaleza que podían surgir personas tan excepcionales en la fe como Fr. Pedro de Urraca. A través de sujetos como este hombre santo, el Nuevo Mundo y específicamente el Perú se integraban al mundo católico de una manera más plena, pues ellos mostraban que la cristianización daba frutos valorados por toda la Iglesia. El tema de la identidad nacional también estuvo presente en la obra de Colombo, quien, dada su calidad de peninsular, tendió a rescatar el origen castellano de Urraca, sin menoscabar la significación que tuvo el Nuevo Mundo en su vida. La valoración de la patria la destaca al referirse al hogar y a la educación que allí se le entregó que lo marcará para toda su vida. También en su vuelta a España con el Príncipe de Esquilache, que la atribuye a un designio divino para que pudiera de esa manera dejar allí su impronta de hombre santo y para que su patria pudiera gozar "de los rayos de su virtud".

Uno los aspectos más de fondo que se desprenden de las obras analizadas tiene que ver con la imbricación entre las hagiografías y el proceso de beatificación. Se produce una relación en ambos sentidos. Las hagiografías influyen en el proceso y este, en algunos casos, orienta la estructura y contenido de las hagiografías. Las hagiografías fueron escritas para influir favorablemente en el camino a la santidad del Siervo de Dios. Se suponía que aportarían argumentos a la causa ya fuese contribuyendo a demostrar la fama de hombre santo que poseyó entre sus contemporáneos o mostrando los favores que, después de muerto y por su intermedio, hizo Dios. Todo parece indicar que la primera hagiografía, que terminó siendo la más importante, cumplió con lo que acabamos de señalar, pero el resultado estuvo lejos de ser beneficiosa para la causa. En buena medida el que esta se hubiese prolongado por 310 años es en parte consecuencia de la obra de Fr. Francisco Messía. Ella fue la base de las otras hagiografías y marcó la pauta en cuanto a los acontecimientos que reflejarían la cotidianeidad de la vida del Siervo de Dios. Si bien en cuanto a 
contenido estaba en consonancia con lo que aun se estilaba en Europa y en América en el siglo XVII, no es menos cierto que en la Santa Sede y entre ciertos teólogos estaba en desarrollo una tendencia crítica respecto de la valoración exagerada de los dones gratuitos y de los hechos milagrosos que dejaban en un segundo plano a las gracias santificantes. En el caso español se agregaba una desconfianza hacia las experiencias milagrosas vinculadas a la oración como consecuencia de la eclosión del iluminismo. En la medida que el proceso se fue prolongando en el tiempo, más notorio se hacía el desfase entre el tipo de santidad que la Santa Sede trataba de promover y la imagen que proyectaba la hagiografía de Messía.

Pero todavía más, el asunto es que aquella obra influyó en las siguientes y por lo tanto también las contaminó con una exagerada presencia de lo maravilloso. La hagiografía de Colombo intentó atenuar levemente los excesos, pero en la medida que siguió, tanto en la forma como en el fondo, a la obra de Messía, los cambios no alteraron la imagen proyectada. La hagiografía anónima apuntó sobre todo a remediar otro de los vacíos que tenía aquella, como era el tema de la práctica de las virtudes, que el autor-confesor trató someramente. Ahí hizo un aporte novedoso, que no fue suficiente para cambiar el curso del proceso. Y esto por un factor clave. La obra de Messía fue mucho más que una hagiografía que debía incorporarse a la causa como antecedente. En razón a la labor que desempeñó su autor en la primera etapa del proceso, como impulsor de la causa y luego procurador de ella, da la impresión que proporcionó antecedentes para la elaboración del cuestionario a los testigos, amén de que varios de estos la leyeron y la citaron como fuente en sus declaraciones ante los jueces eclesiásticos. Por lo mismo, de manera directa o indirecta terminó condicionando el proceso en su conjunto. La llegada a buen término de la causa coincidió con una reorientación de la misma, que se centró en la valoración del ejercicio de las virtudes y le quitó protagonismo al papel predominante que habían tenido los dones sobrenaturales, haciéndolo en términos parecidos a como se reflejaban en la última biografía.

Todo lo anterior nos muestra cómo una hagiografía, la de Messía, escrita por el confesor, nada más morir el protagonista, y que quedó inédita, pudo, no obstante, contribuir, de manera directa e indirecta, a formar una determinada imagen de un sujeto, que se prolongó en el tiempo y que es la que hasta hoy, en lo fundamental, tienen de él los miles de devotos que acuden por favores ante su tumba y su cruz de penitente, que se encuentran en el convento de la Merced de Lima. En consecuencia, creemos que a través del análisis de este caso es factible apreciar una de las formas como las hagiografías, más allá de las relaciones con los procesos de santidad, podían influir en la conformación de una conciencia colectiva.

\section{RESUMEN}

El artículo analiza cuatro hagiografías, dos de ellas inéditas, que se escribieron en diferentes épocas sobre el Venerable Fr. Pedro de Urraca, que nació en Jadraque, España, en 1583 y murió en Lima, en fama de santidad, en 1657. Se estudia el contenido y objetivo de las obras con el fin de apreciar las diferencias que presentan y las variaciones en el tiempo que, desde la perspectiva de la mentalidad religiosa, reflejan. Pero también se examina la relación 
que tuvieron con el proceso de beatificación del protagonista, para tratar de entender la influencia que ejercieron en dicho proceso. Al mismo tiempo, se pretende ver la manera como este contribuyó a marcar las características y orientación de las obras. En ese contexto, postulamos que la primera de las hagiografías, la que se escribió un mes después de la muerte del Siervo de Dios y que aún permanece inédita, tuvo una gran influencia en la orientación de la causa de beatificación y hasta cierto punto marcó su trayectoria y también influyó, directa o indirectamente, en las hagiografías que se escribieron con posterioridad.

Palabras clave: Hagiografía, canonización, santidad, religiosidad.

\begin{abstract}
This article analyzes four hagiographies-two of them unpublished-that were written in different periods about the Venerable Friar Pedro de Urraca, who was born in Jadraque, Spain, in 1583, and died in Lima, renowned for his sanctity, in 1657. The author studies the content and objective of these literary works with the purpose of appreciating the differences and the variations over time that they present and reflect, from the perspective of religious mentality. However, the author also examines the relation they had with the process of beatification of the protagonist, in order to try to understand the influence that they exercised on said process. At the same time, the author attempts to see the way in which this process left its traces on the characteristics and direction of the works. In this context, the author proposes that the first of the hagiographies, written within a month of the death of this Servant of God and still unpublished, had a great influence on the direction that the cause of beatification took and, up to a certain point, marked the trajectory of the beatification process. The author also claims that this first hagiography influenced, directly or indirectly, the hagiographies that were written afterwards.
\end{abstract}

Key words: Hagiography, Canonization, Holiness, Religiosity. 